\title{
Modelling the evolution of the archaeal tryptophan synthase
} Rainer Merkl*

\author{
Address: Institut für Biophysik und Physikalische Biochemie, Universität Regensburg, 93040 Regensburg, Germany \\ Email: Rainer Merkl* - Rainer.Merkl@Biologie.uni-regensburg.de \\ * Corresponding author
}

Published: 10 April 2007

BMC Evolutionary Biology 2007, 7:59 doi:10.1186/147/-2/48-7-59

This article is available from: http://www.biomedcentral.com/I47I-2/48/7/59

(c) 2007 Merkl; licensee BioMed Central Ltd.

This is an Open Access article distributed under the terms of the Creative Commons Attribution License (http://creativecommons.org/licenses/by/2.0), which permits unrestricted use, distribution, and reproduction in any medium, provided the original work is properly cited.
Received: I3 February 2007

Accepted: 10 April 2007

\begin{abstract}
Background: Microorganisms and plants are able to produce tryptophan. Enzymes catalysing the last seven steps of tryptophan biosynthesis are encoded in the canonical trp operon. Among the trp genes are most frequently trpA and $\operatorname{trp} B$, which code for the alpha and beta subunit of tryptophan synthase. In several prokaryotic genomes, two variants of $\operatorname{trp} B$ (named $\operatorname{trp} B /$ or trpB2) occur in different combinations. The evolutionary history of these trpB genes is under debate.

Results: In order to study the evolution of trp genes, completely sequenced archaeal and bacterial genomes containing $\operatorname{trp} B$ were analysed. Phylogenetic trees indicated that $\operatorname{TrpB}$ sequences constitute four distinct groups; their composition is in agreement with the location of respective genes. The first group consisted exclusively of $\operatorname{trpBI}$ genes most of which belonged to trp operons. Groups two to four contained trpB2 genes. The largest group (trpB2_o) contained trpB2 genes all located outside of operons. Most of these genes originated from species possessing an operonbased trpB $I$ in addition. Groups three and four pertain to trpB2 genes of those genomes containing exclusively one or two trpB2 genes, but no $\operatorname{trpB}$. One group (trpB2_i) consisted of $\operatorname{trp} B 2$ genes located inside, the other (trpB2_a) of $\operatorname{trpB} 2$ genes located outside the trp operon. $\operatorname{Trp} A$ and $\operatorname{Trp} B$ form a heterodimer and cooperate biochemically. In order to characterise $\operatorname{trp} B$ variants and stages of $\operatorname{TrpA} / \operatorname{TrpB}$ cooperation in silico, several approaches were combined. Phylogenetic trees were constructed for all trp genes; their structure was assessed via bootstrapping. Alternative models of $\operatorname{trp} B$ evolution were evaluated with parsimony arguments. The four groups of $\operatorname{trp} B$ variants were correlated with archaeal speciation. Several stages of $\operatorname{TrpA} / \operatorname{Trp} B$ cooperation were identified and $\operatorname{trp} B$ variants were characterised. Most plausibly, $\operatorname{trp} B 2$ represents the predecessor of the modern $\operatorname{trp} B$ gene, and trpBI evolved in an ancestral bacterium.
\end{abstract}

Conclusion: In archaeal genomes, several stages of $\operatorname{trp} B$ evolution, $\operatorname{Trp} A / \operatorname{Trp} B$ cooperation, and operon formation can be observed. Thus, archaeal trp genes may serve as a model system for studying the evolution of protein-protein interactions and operon formation.

\section{Background}

The synthesis of tryptophan is a common metabolic capability of microorganisms and higher plants, which is not provided by mammals. The prokaryotic trp operon encodes the enzymes catalysing the final and pathway- specific steps from chorismate to L-tryptophan. For more than 40 years, the enterobacterial operon has now been the classical model system for studying the evolutionary relation of genes and enzymes (see $[1,2]$ and references therein) as well as gene regulation. Considering gene reg- 
ulation, several, conceptually quite different mechanisms have been described for the trp operon. Most of them were elucidated in bacterial species (see e.g. [3-5], and references therein). However, regulation of trp operon expression has also been shown for the archaea Methanothermobacter thermoautotrophicus [6,7] and Thermococcus kodakaraensis [8]. The reason for an elaborated regulation may be the fact that tryptophan is one of the amino acids, whose biochemical synthesis is very expensive [9]. Besides regulation, other features of tryptophan biosynthesis have been studied extensively. The composition of the operon and several aspects of its evolution have been analysed [10], and for each enzyme, at least one 3D-structure has been determined. Taken together, the trp operon is besides the ribosomal protein operons one of the best-characterised gene clusters occurring in microorganisms. Its investigation has provided fundamental insights into many aspects of bacterial genetics and enzymology; see [2].

The canonical $\operatorname{trp}$ operon encodes seven enzymes responsible for the synthesis of L-tryptophan from chorismate. The first reaction is catalysed by the anthranilate synthase, a glutamine amidotransferase, which is a complex consisting of the larger synthase (TrpE) and a smaller glutaminase (TrpG) subunit. The anthranilate phosphoribosyl transferase (TrpD) provides the glutamine amidotransferase function that allows glutamine to serve as the amino donor in anthranilate formation. The two subsequent enzymes, $\operatorname{TrpF}$ and $\operatorname{TrpC}$, catalyse the isomerisation of phosphoribosylanthranilate and the synthesis of indole-3-glycerol phosphate, respectively.

TrpA and TrpB constitute the $\alpha \beta \beta \alpha$ tryptophan synthase complex which catalyses the final reaction from indole-3glycerole phosphate + L-serine to L-tryptophan $+\mathrm{H}_{2} \mathrm{O}$. The $\alpha$ subunit (TrpA) cleaves indoleglycerol-3-phosphate to glyceraldehyde-3-phosphate and indole. The latter is transported through a hydrophobic tunnel to the associated $\beta$ subunit (TrpB), where it is condensed with L-serine to yield L-tryptophan [11]. A sophisticated mechanism of allostery links the $\alpha$ and $\beta$ monomers of the synthase; see e.g. [12].

Several Trp enzymes represent paradigmatically larger classes of proteins having similar function or protein architecture: TrpG is similar to HisH (an enzyme involved in histidine biosynthesis) and other glutaminases of type I glutamine amidotransferases [13]. TrpF, TrpC and TrpA are all $(\beta \alpha)_{8}$ barrels possessing similar phosphate binding sites [14]. The basic $(\beta \alpha)_{8}$ barrel is the most common enzyme fold in the PDB database of known protein structures [15].
For the bacterial trp genes, the following order was determined: large anthranilate synthase subunit (trpE), small anthranilate synthase subunit ( $\operatorname{trp} G)$, anthranilate phosphoribosyl transferase (trpD), indole-3-glycerol phosphate synthase $(\operatorname{tr} p C)$, phosphoribosyl anthranilate isomerase $(\operatorname{trp} p)$, tryptophan synthase $\beta$ subunit $(\operatorname{trp} B)$ and tryptophan synthase $\alpha$ subunit ( $\operatorname{trp} A)$, or abbreviated $\operatorname{trpEGDCFBA~[16].~The~gene-fusions~trpGD~and~trpEG~have~}$ been observed in several species; moreover, in other genomes, the operon is broken up into several gene clusters. In archaeal genomes, order of trp genes is highly variable. In Sulfolobus solfataricus, an intact operon $\operatorname{trpBADFEGC}$ is observed. In Haloferax volcanii, the trp operon is divided into two isolated clusters, $\operatorname{trp} C B A$ and trpDFEG, separated by more than $1200 \mathrm{~kb}$. In the genome of Natronomonas pharaonis, there exist three homologs of $\operatorname{trp} D$ and two homologs of $\operatorname{trpB}$, $\operatorname{trpE}$ and $\operatorname{trpG}$ each. Pyrococcus horikoshii completely lacks the genes for tryptophan synthesis (and for other aromatic amino acids).

The genes $\operatorname{trp} B, \operatorname{trp} A$ and $\operatorname{trp} E, \operatorname{trp} G$ are frequently in the same order and in close proximity, i.e. they comprise the linkage groups $\operatorname{trp} B A$ and $\operatorname{trpEG}$. In both cases, the gene products constitute a bienzyme complex, whose active centres interact with each other. Because they occur in both bacterial and archaeal genomes, these linkage groups have been identified as ancestral [16]. A reconstruction of the tentative ancestral $\operatorname{trp}$ operon is hampered by the observation that trp genes are poor phylogenetic reporters. Different rates of evolution, multiple gene duplications and convergent evolution, as a consequence of specific adaptation to environmental demands, may be the reason for inconsistencies seen in comparisons of phylogenies deduced from trp genes or rRNA [16]. Therefore, the evolution of each element of the trp operon has to be examined separately.

For evolutionary studies, tryptophan synthase is an especially interesting candidate. This enzyme has been analysed for decades in order to understand the structural basis and functional consequences of protein-protein interactions [17]. The isolated TrpA and TrpB proteins form stable, however poorly active $\alpha$ monomers and $\beta \beta$ homodimers, respectively $[18,19]$. Their assembly to the native $\alpha \beta \beta \alpha$ complex induces conformational changes in both subunit types, as shown by X-ray crystallography for the Pyrococcus furiosus synthase [18]. The result of this communication between the $\alpha$ and $\beta$ subunits is a reciprocal activation by one to two orders of magnitude [20]. Conformational changes crucial for the allosteric communication between the active sites of the $\alpha$ - and $\beta$-subunits have been analysed in detail for the Salmonella typhimurium tryptophan synthase; see e.g. [21-24]. 
The role of the $\beta$-subunit is of particular importance for the evolution of Trp synthase. For archaea and bacteria, it is known that two variants of $\operatorname{trp} B$ genes occur, which can clearly be distinguished by their protein sequences [25]. The major group, harbouring proteins of type TrpB1 includes the enzymes of enterobacteria and Bacillus subtilis. The minor group (denoted TrpB2) contains many archaeal proteins. Most prokaryotes like E. coli possess a single trpB1 gene. However, in several bacterial and archaeal genomes, a combination of one $\operatorname{trp} B 1$ and one trpB2 gene occurs. In addition, some species exist, which have only one or two $\operatorname{trp} B 2$, but no $\operatorname{trp} B 1$ gene. This variety prompted us to characterise the evolution of TrpB and its interaction with TrpA in detail, both biochemically and in silico.

Based on biochemical findings, a model for the evolution of the tryptophan synthase complex has recently been introduced [26]. This model assumes the existence of an ancient and non operon-based $\operatorname{trpB2}$. After duplication, only one trpB2 gene presumably has been integrated into the trp operon. Differences in evolutionary pressure may have been responsible for the divergence of non operonand operon-based $\operatorname{trp} B$ genes. The coevolution with $\operatorname{trp} A$ may have led to a better adapted $\operatorname{trpB1}$. The data on complex formation and subunit activation led us consider existing $\operatorname{trp} B$ variants as representatives of evolutionary steps in the postulated model.

In this study, I have assessed this model by phylogenetic methods. Two basic questions have been addressed: $i$ ) What is the evolutionary relationship of $\operatorname{trpB} 1$ and $\operatorname{trp} B 2$ ? ii) How did extant archaeal trp operons evolve? Extending previous work [25], I will discuss novel hypotheses concerning the properties of TrpB2 and operon formation. Based on the content of 26 completely sequenced archaeal genomes, comparative analyses of trp sequences, and their locations in genomes will be reported in order to reconstruct the evolution of TrpB-type subunits and of the coevolution of $\operatorname{TrpA} / \operatorname{TrpB}$. It will be shown that $\operatorname{TrpB} 2$ variants represent different stages of $\operatorname{TrpA} / \operatorname{TrpB}$ cooperation and that TrpB2 is favoured over TrpB1 in certain environments. Moreover, TrpB2 has features of a more ancient TrpB variant.

\section{Results and Discussion}

\section{Assessing the composition of trp gene clusters}

In order to describe the composition of trp regulons in a quantitative manner and to compare their content in archaeal and bacterial genomes, AMIGOS [27] was used. By comparing genomes, this program identifies gene clusters and rates each individual cluster element with a con$s_{C L}$-score. The cons $_{C L}$-score of an individual gene depends on $i$ ) the occurrence of this gene in a given gene cluster and $i$ ) the global similarity of the genomes harbouring these clusters. Thus, individual scores assess both the relatedness of genomes and the frequency with which individual genes are members of a cluster. The higher a score, the more pronounced is the occurrence of an individual gene in a given gene cluster. Table 1 lists $\operatorname{cons}_{C L^{-}}$ scores for elements of archaeal and bacterial trp operons. The numbers indicate that in bacteria the clustering of $\operatorname{trp} A$ and $\operatorname{trp} B 1$ was stronger than that of all other trp genes. In archaeal genomes, the clustering of $\operatorname{trp} E$ and $\operatorname{trp} G$ was most prominent. A reason for the lower score of $\operatorname{trp} B$ in archaeal $\operatorname{trp}$ operons was the occurrence of two $\operatorname{tr} p B$ variants $(\operatorname{trpB} 1$ and $\operatorname{trpB2})$ in these species. The scores signalled that $\operatorname{trpB1}$ was more frequently part of an trp operon than $\operatorname{trp} B 2$. Moreover, the score for $\operatorname{trp} A$ was lower than that of $\operatorname{trpE}$ or $\operatorname{trpG}$. It follows for archaea that $\operatorname{trp} A$ and $\operatorname{trp} B$ are less strictly integrated into trp operons than in bacteria. This suggests that either evolutionary pressure responsible for operon formation is less pronounced or that additional selective forces disfavour the integration of $\operatorname{trp} A$ and $\operatorname{trp} B$ into certain archaeal trp operons.

It has been hypothesised that TrpB2 possesses a second function and acts as a serine deaminase [25]. This prediction has been deduced from the analysis of phyletic patterns, i.e. the absence of an encoded serine deaminase function in certain genomes. However, it has been shown that TrpB1 of Thermotoga maritima and TrpB2_o proteins of Sulfolobus solfataricus and T. maritima have poor serine deaminase activities [26]. An alternative method of nonhomologous gene annotation is the exploitation of gene neighbourhoods [28], as e.g. implemented with AMIGOS. For $\operatorname{trpB2}$, AMIGOS did not detect a second conserved gene neighbourhood besides the one constituting trp operons. Thus, no clues for an additional function besides tryptophan synthesis have been deduced for trpB2 by this approach.

\section{A naming code for trpB genes}

The two variants of $\operatorname{trp} B$ occur in various genomes in different combinations [25]. In order to facilitate the analysis of phylogenetic trees, a naming scheme was introduced. Names of genes and gene products were generated according to the scheme SPECIES_LOC|TYPE|TAX. Here, SPECIES is an abbreviation of the species name (see Materials). LOC indicates the position of the specific $\operatorname{trpB}$ gene relative to a putative trp operon (more precisely: relative to a $\operatorname{trp} A$ gene). If two $\operatorname{trp} B$ genes occur in a genome, they were labelled_i (if the gene was located inside the trp operon) or _o (if located outside the operon). If only a single $\operatorname{trp} B$ gene occurred in the genome, it was labelled_s, if the gene was linked to $\operatorname{trp} A$, and it was labelled _S, if it was separate from $\operatorname{trpA}$. TYPE indicates the gene type. It is 1 for $\operatorname{trpB1}$ and 2 for $\operatorname{trpB2}$. Finally, TAX gives the taxonomical classification. It is C for Crenarchaeota, E for Euryarchaeota and B for Bacteria. The following examples 
Table I: cons $_{c l}$ scores for trp genes

\begin{tabular}{|c|c|c|c|c|}
\hline \multicolumn{2}{|c|}{ cons $_{\mathrm{Cl}}-$ values } & \multirow[t]{2}{*}{ Protein } & \multirow[t]{2}{*}{ COG \# } & \multirow[t]{2}{*}{ Function } \\
\hline Archaea & Bacteria & & & \\
\hline 2.0 & 2.8 & TrpE & COG0I47 & anthranilate/para-aminobenzoate synthases comp. I \\
\hline 2.1 & 2.7 & TrpG & COG05I2 & anthranilate/para-aminobenzoate synthases comp. II \\
\hline 1.8 & 2.3 & TrpF & COG0I35 & phosphoribosylanthranilate isomerase \\
\hline 1.8 & 2.9 & TrpC & COG0I34 & indole-3-glycerol phosphate synthase \\
\hline 1.9 & 3.0 & TrpA & COG0I59 & tryptophan synthase alpha chain \\
\hline 1.4 & 3.0 & TrpBI & COG0I33 & tryptophan synthase beta chain \\
\hline 0.6 & - & TrpB2 & COGI350 & paralogue of $\operatorname{Trp} B$ \\
\hline 1.9 & 2.6 & TrpD & COG0547 & anthranilate phosphoribosyltransferase \\
\hline
\end{tabular}

Note: The first two columns list score values deduced from representative sets of archaeal and bacterial genomes. Columns three and four list protein names, COG numbers, and protein function. The cons $_{c \mid}$-scores were determined by using AMIGOS [27]. COG numbers indicate orthologous gene clusters as defined in the COG database [29].

explain how to resolve sequence names: Aperni_o2C was used to name a $\operatorname{trp} B$ gene in the genome of Aeropyrum pernix (Aperni), which occurred outside the trp operon (_o) and was of type $\operatorname{trpB2}(2)$. As A. pernix is a Crenarchaeota, the name ends with a $\mathrm{C}$. The _o notation indicates that a second $\operatorname{trp} B$ gene exists in $A$. pernix. This gene was consequently named Aperni_i2C, as it is a $\operatorname{trpB2}$ gene inside the trp operon. Note that also pairs like Tmarit_i1B and Tmarit_o2B exist indicating the occurrence of a $\operatorname{tr} p B 1$ gene inside and a trpB2 gene outside the trp operon. Sacido_s2C is the designation of a $\operatorname{trpB2}$ gene located inside the trp operon. As Sulfolobus acidocaldarius possesses only one $\operatorname{trp} B$ gene, it was labelled with a _s. Since Thermoplasma volcanium possesses only one $\operatorname{trp} B$ gene, which is non operon-based and of type $\operatorname{trpB2}$, this gene was named Tvolc_S2E. Designations of the encoded proteins were assigned in a corresponding way.

\section{Determining the occurrence of trpB genes}

In order to determine the distribution of $\operatorname{trp} B$ variants, the COG [29] and the STRING database [30] were used. For all completely sequenced archaeal and bacterial genomes, their occurrence was determined and their location was identified. Depending on the occurrence of $\operatorname{tr} p B$ variants, archaeal species were grouped into five categories, named species-types in the following. Note that these speciestypes characterise the content of genomes. Links to the above naming scheme for genes are gene location and type.

As Table 2 shows, there were six archaeal genomes possessing a single $\operatorname{tr} p B$ gene of class $\operatorname{trpB1}$ ( $s 1$ or $S 1$ species), four genomes with a single $\operatorname{trp} B$ gene of class $\operatorname{trp} B 2$ ( $s 2$ or $S 2$ species), five genomes harbouring one operon-based and one additional, non operon-based $\operatorname{trpB2}$ each (i2_o2 species), ten species of type $i 1 \_o 2$ (one operon-based $\operatorname{trpB} 1$ and one additional $\operatorname{trpB2}$ gene) and one species possessing one operon-based and at least one non operon- based trpB1 gene (i1_o1 species). The most frequent combination ( 10 out of 26 ) was an operon-based $\operatorname{trpB} 1$ and a non operon-based trpB2 gene ( $i 1 \_o 2$ species). N. pharaonis was the only archaeal species of type i1_o1. All five completely sequenced Crenarchaeota possess exclusively genes of class $\operatorname{trpB2}$.

Bacterial species did not contribute species-types noticeably different from those observed among archaea (data not shown). Both Geobacter species represent special cases most plausibly explained by ongoing genomic rearrangements: Gsulfu_i2B is an operon-based trpB2 gene of type TrpB2_o. The trp operon of G. sulfurreducens harbours both a $\operatorname{trpB} 1$ and a $\operatorname{trpB} 2$ gene. According to the annotation, the $\operatorname{trpB1}$ gene (Locus tag GSU2375) contains a frameshift and is annotated as a pseudogene [31]. A direct neighbour of $\operatorname{trpB1}$ in G. metallireducens is a transposase, making a recent transfer of this gene plausible. In comparison to archaea, the occurrence of $\operatorname{trpB} 2$ was less frequent in bacterial genomes and none contained exclusively trpB2 genes.

\section{Assessing phylogenetic relationship of trp genes}

Sequences originating from all archaea and several representative bacteria were selected for a phylogenetic classification of trp genes. Multiple sequence alignments were created by using M-Coffee [32], and trees were constructed and evaluated using SplitsTrees [33]. Figures 1, 2, 3, 4 are plots of unrooted trees generated for protein sequences of $\operatorname{Trp} A, \operatorname{TrpB}, \operatorname{TrpD}, \operatorname{TrpE}$, and $\operatorname{TrpG}$. In order to assess the statistical strength of individual edges, bootstrap resampling was used. For relevant edges, bootstrap values were plotted; see Figures 1, 2, 3, 4. The trees were analysed in detail, as follows.

\section{$\operatorname{TrpB}$}

In agreement with previous findings [25], TrpB1 and TrpB2 clearly fall into two distinct groups. This distinction 
Table 2: Classifying known archaeal genomes according to the occurrence of trpB genes

\begin{tabular}{|c|c|c|c|c|}
\hline$S 2(3), s 2(1)$ & i2_02 (5) & iI_o2(10) & il_ol (I) & $S I(I), s I(5)$ \\
\hline $\begin{array}{l}\text { S. acidocaldarius, s2C 3, TA } \\
\text { T. volcanium, S2E 3, TA } \\
\text { T. acidophilum, S2E 3, TA } \\
\text { P. horikoshii, S2E 2, HT }\end{array}$ & $\begin{array}{l}\text { A. pernix, i2C } 4, \text { o } 2 \mathrm{C} 2 \text {, HT } \\
\text { P. aerophilum, i2C } 3, \text { o } 2 \mathrm{C} 4 \text {, } \\
\text { HT } \\
\text { P. torridus, i2E } 2, \text { o } 2 \mathrm{E} 2 \text {, TA } \\
\text { S. solfataricus, i2C } 3, \text { o2C } 3 \text {, } \\
\text { TA } \\
\text { S. tokodaii, i2C } 3, \text { o2C } 4 \text {, } \\
\text { TA }\end{array}$ & $\begin{array}{l}\text { A. fulgidus, i IE 2, o2E 6, HT } \\
\text { M. acetivorans, iIE I, o2E 5, } \\
\text { MS } \\
\text { M. barkeri, iIE I, o2E 4, MS } \\
\text { M. burtonii, iIE I, o2E 4, MS } \\
\text { M. hungatei, iIE I, o2E 4, } \\
\text { MS } \\
\text { M. mazei, iIE I, o2E 5, MS } \\
\text { M. thermoautotrophicus, i IE } \\
\text { I, o2E 3, TP } \\
\text { P. abyssi, iIE 3, o2E 2, HT } \\
\text { P. furiosus, iIE 3, o2E 2, HT } \\
\text { T. kodakaraensis, iIE 2, o2E } \\
\text { 2, HT }\end{array}$ & $\begin{array}{l}\text { N. pharaonis, ilE I, olE 0, } \\
\text { HP }\end{array}$ & $\begin{array}{l}\text { M. kandleri, SIE 4, YP } \\
\text { Halobacterium, sIE I, HP } \\
\text { H. marismortui, sIE I, HP } \\
\text { M. maripaludis, s IE I, MS } \\
\text { M. stadtmanae, s IE I, MS } \\
\text { M. jannaschii, sIE 2, YP }\end{array}$ \\
\hline 2.75 & i2: $3.0,02: 3.0$ & il: $1.6,02: 3.7$ & il: 1.0, ol: 0.0 & 1.6 \\
\hline
\end{tabular}

\begin{abstract}
Note: The occurrence and the location of $\operatorname{trp} B$ genes were coded according to the following scheme used in the top line: $S 2$ species possess exactly one, non operon-based trpB2 gene, $s 2$ : ditto, the gene is located inside the trp operon. trpBI was treated analogously. i2_o2 are species possessing an $\operatorname{trpB2}$ gene inside and a second $\operatorname{trpB2}$ outside the operon, $i I \_02$ are species with an operon-based trpBI and a non operon-based trpB2, and $i I \_01$ are species possessing an operon-based and at least one non operon-based trpBI. The number of genomes having the same species-type is given in brackets. The acronyms following the species name classify trpB genes; see Results. Numbers give tryptophan codons occurring in the respective gene. The abbreviations indicate hyperthermophilic (HT), thermoacidophilic (TA), thermophilic (TP), mesophilic (MS), halophilic (HP), or hyperthermophilic + halophilic species (YP). The last line of the table gives mean values for the occurrence of tryptophan codons.
\end{abstract}

was supported by a high bootstrap value; see Figure 1 . Moreover, among TrpB2 sequences a finer sub-clustering could be deduced, which was in agreement with the location of the genes. One group (labelled TrpB2_o) consisted of products of $\operatorname{trpB2}$ genes not located in operons. 14 out of 16 elements were TrpB2 sequences originating from i1_o2 species, i.e. species possessing besides an isolated lying $\operatorname{trpB2}$ an additional, operon-based $\operatorname{trp} B 1$. The genes Paerip_o2C and Aperni_o2C of the two i2_o2 species Pyrobaculum aerophilum and $A$. pernix belonged to this group too. These two species possess a $\operatorname{trp}$ operon containing a $\operatorname{trpB2}$ gene. Bacterial TrpB2_o sequences, which originated from the $11 \_02$ species T. maritima and G. metallireducens did not form an isolated subtree. This finding argues for a common origin of bacterial and archaeal trpB2_o genes.

The other two subgroups of $\operatorname{TrpB} 2$ variants were clearly distinct from the TrpB2_o cluster. The sequences of these clusters originated from archaeal S2 (Thermoplasmataceae), s2 or i2_o2 species (Sulfolobaceae, Picrophilus torridus, A. pernix, P. aerophilum), i.e. species possessing exclusively one or two $\operatorname{trpB2}$ genes. These sequences formed two clearly separated sets. The first set, named TrpB2_i, subsumes operon-based trpB2 genes, and harboured Stokod_i2C, Sacido_s2C, Ssolfa_i2C, Ptorri_i2E, Apern_i2C, and Paerop_i2C. The second set, named TrpB2_a, consisted of Ptorri_o2E, Stokod_o2C, Ssolfo_o2C, Tacido_S2E, and Tvolca_S2E, and subsumed trpB2 genes located outside trp operons. For Thermoplasma volcanium and Thermoplasma acidophilum, these trpB2 genes were the only $\operatorname{trpB}$ genes, for $S$. solfataricus, $S$. tokodaii and $P$. torridus, a second, however distinguishable $\operatorname{trp} B 2$ gene of type $\operatorname{trpB2} i$ was part of the $\operatorname{trp}$ operon. Proteins of type TrpB2_i formed two finer subgroups: Those of $P$. torridus and the Sulfolobaceae resembled more sequences of TrpB2_a. Those of A. pernix and P. aerophilum, which possess a non operon-based trpB2_o gene, were different both from TrpB2_a and from TrpB2_o sequences; see Figure 1. All relevant edges separating these groups are due to their high bootstrap value statistically highly significant.

As a single exception, the genome of $P$. horikoshii did not follow the general classification scheme. It possesses a single $\operatorname{trpB2}$ gene, which is of type $\operatorname{trpB2} o$ and not - as expected - of type trpB2_a. However, this genome lacks all the other trp genes, which has been previously interpreted as reductive evolution [10]. The occurrence of a $\operatorname{trpB2}{ }_{-} \mathrm{o}$ gene might be due to the loss of the complete trp operon after speciation of $\operatorname{trpB} 2 \_i$ and $\operatorname{trp} B 2 \_o$. The fact that the $P$. horikoshii trpB2_o gene was not affected by the reduction has been considered as an argument for assigning to it an other selective function [25], which has not been identified yet. As noted above, the two bacterial Geobacter species represent special cases associated with the presumptive rearrangement of $\operatorname{trp}$ genes. Briefly, the $\operatorname{tr} p B$ variants can be characterised as follows: $\operatorname{tr} p B 1$ genes occur exclusively in $\operatorname{trp}$ operons. $\operatorname{trpB2}$ _o variants represent genes occurring outside operons in those species that have an operon-based trpB1. Several archaeal species possess 


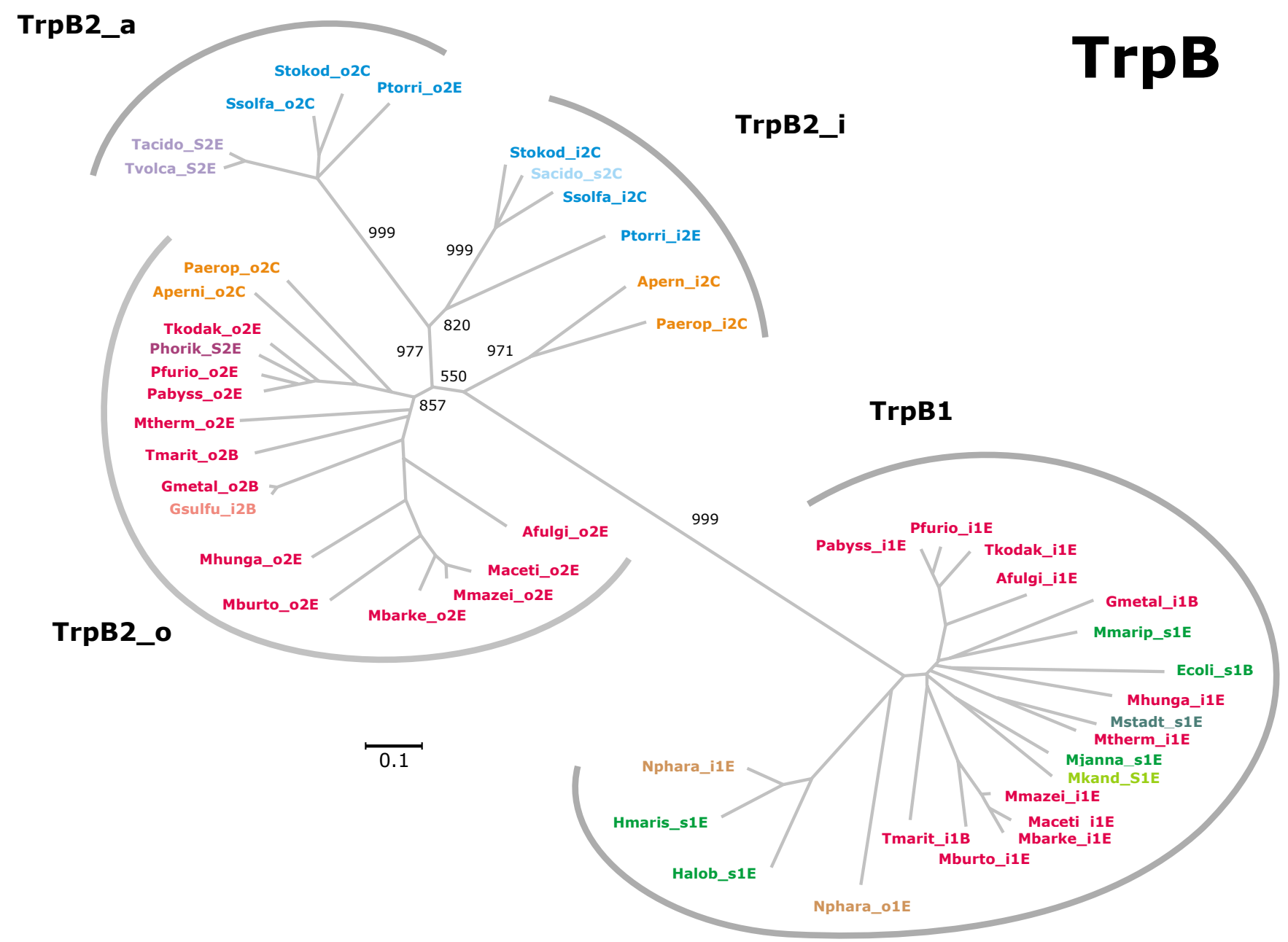

\section{Figure I}

Phylogenetic tree of TrpB sequences. Using archaeal and bacterial TrpB sequences, a multiple sequence alignment was generated and an unrooted phylogenetic tree was constructed. Proteins were labelled according to the naming scheme introduced in the Results section. Subtrees were marked according to the sequence type (TrpBI or TrpB2). TrpB2 sequences span three subtrees; clustering is in agreement with the location of genes. TrpB2_o proteins are all encoded outside operons; 14 out of 16 originate from species that possess an operon-based trpBI in addition. TrpB2_i proteins are encoded inside operons. Each of these genes is accompanied by a non operon-based trpB2. TrpB2_a sequences occur exclusively in genomes that have a single trpB2 gene or occur as a second trpB2 outside an operon in combination with a trpB2_i gene. The numbers are bootstrap values resulting from 1000 replications. Gene names are colour-coded. Blue colours indicate genes occurring in S2 (violet), s2 (light blue) and those i2_o2 species, which possess trpB2_a or trpB2_i genes (dark blue). Orange colours designate trpB2_i and trpB2_o genes. Red colours signify genes of $i l \_02$, S2, or s2 species, and green colours mark genes of $s /$ (light green) or SI (dark green) species. The names of the two trpBI copies occurring in N. pharaonis are printed in brown. For acronyms of species-types, see legend of Table 2. The length of the horizontal bar corresponds to 0.1 substitutions per site.

exclusively $\operatorname{trp} B 2$ genes: If only one $\operatorname{trpB2}$ gene exists, it is of type $\operatorname{trpB2} \_a$, if two $\operatorname{trpB2}$ genes occur, one is an operonbased $\operatorname{trpB} 2 \_i$, the second a $\operatorname{trpB} 2 \_a$, or a $\operatorname{trpB} 2 \_o$ gene.

\section{$\operatorname{TrpA}$}

Correlated with $\operatorname{TrpB}$ speciation, TrpA proteins showed a division into two, statistically highly significant subgroups; see Figure 2. The larger TrpA1 group consisted of TrpA sequences originating from genomes that possess a
trpB1 gene. Most likely, TrpA1 proteins interact with the operon encoded TrpB1 and thus fall into the same class. The smaller TrpA2 group contained exclusively TrpA proteins of species-types $S 2, s 2$, or $i 2 \_o 2$, i.e. TrpA proteins whose putative interaction partner is exclusively a $\operatorname{TrpB} 2$ protein. The high bootstrap value of 1000 (100\%) for the central edge emphasises the distinction made between TrpA1 and TrpA2. S2, s2, i2_o2 species formed three statistically significant subtrees; compare Figure 2 . These har- 


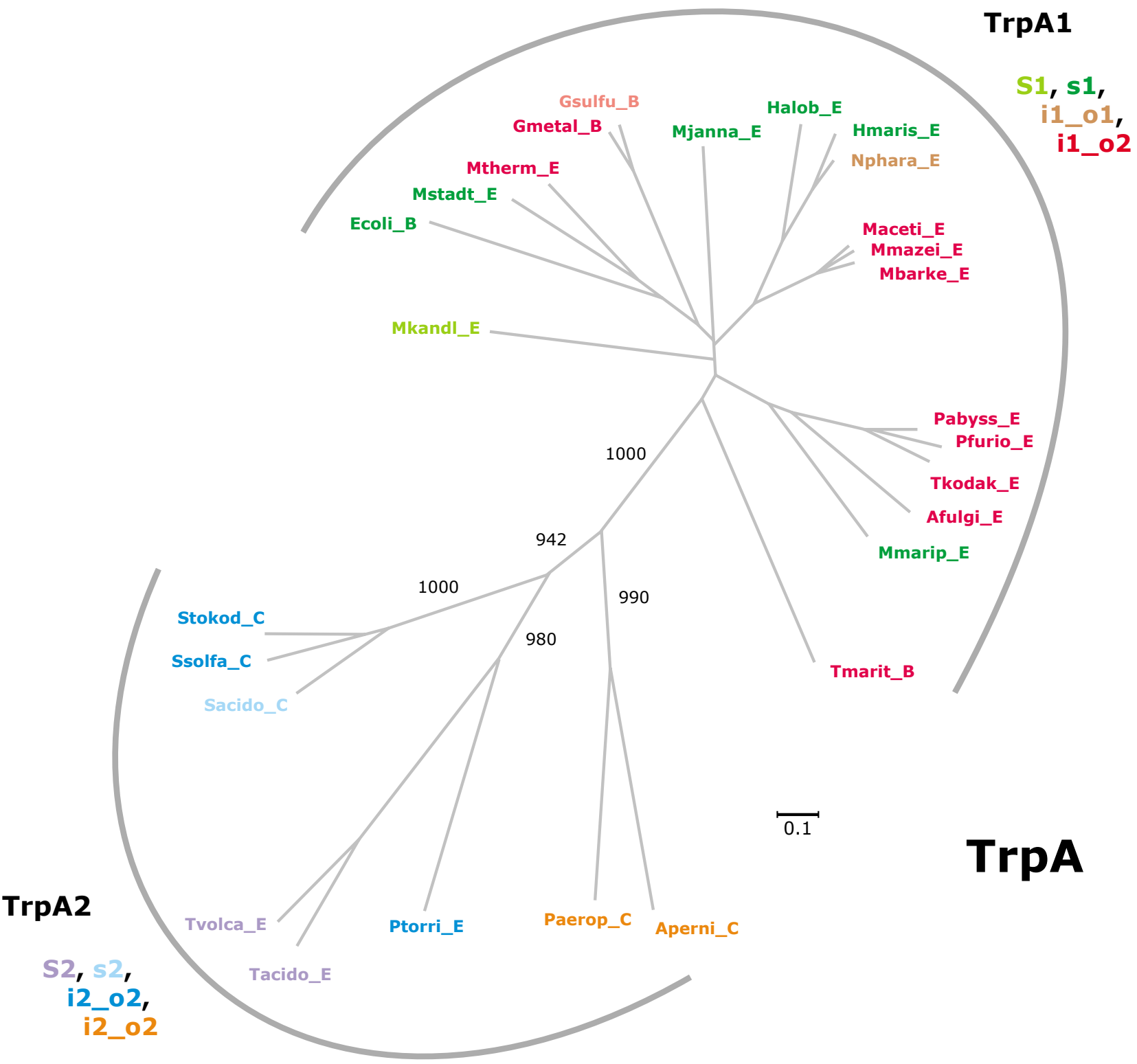

\section{Figure 2}

Phylogenetic tree of archaeal and bacterial TrpA sequences. The two subtrees cluster genomes, which encode at least one trpBI gene (SI, sI, il_ol, or il_o2 species) or which possess only genes of type trpB2 (S2, s2, i2_o2 species). The clusters were named TrpAI or TrpA2, respectively. For abbreviations of sequence names, see Results. For colour code, see legend of Figure I. For the acronyms of species-types, see legend of Table 2.

boured the TrpA sequences of (i) Sulfolobaceae, (ii) Thermoplasmatales (T. acidophilum, T. volcanium, P. torridus) and (iii) P. aerophilum, and A. pernix. The composition of these groups is in agreement with the TrpB2_a and TrpB2_i groups in Figure 1 and indicates the coevolution of $\operatorname{trpB2}$ variants with $\operatorname{trp} A$.
TrpD, TrpE, and TrpG

In all three trees (see Figures 3 and 4), both the proteins of Thermoplasmatales and of the three Sulfolobaceae constituted sub-clusters. The edges determined for TrpD or TrpE entries of these species have similar lengths as those calculated for TrpA or TrpB. Especially for the $\operatorname{trp} A$ and $\operatorname{trpB}$ genes of these species, an increased rate of evolution has been previously postulated [25]. However, the comparison of trees and edge lengths showed that in these species 


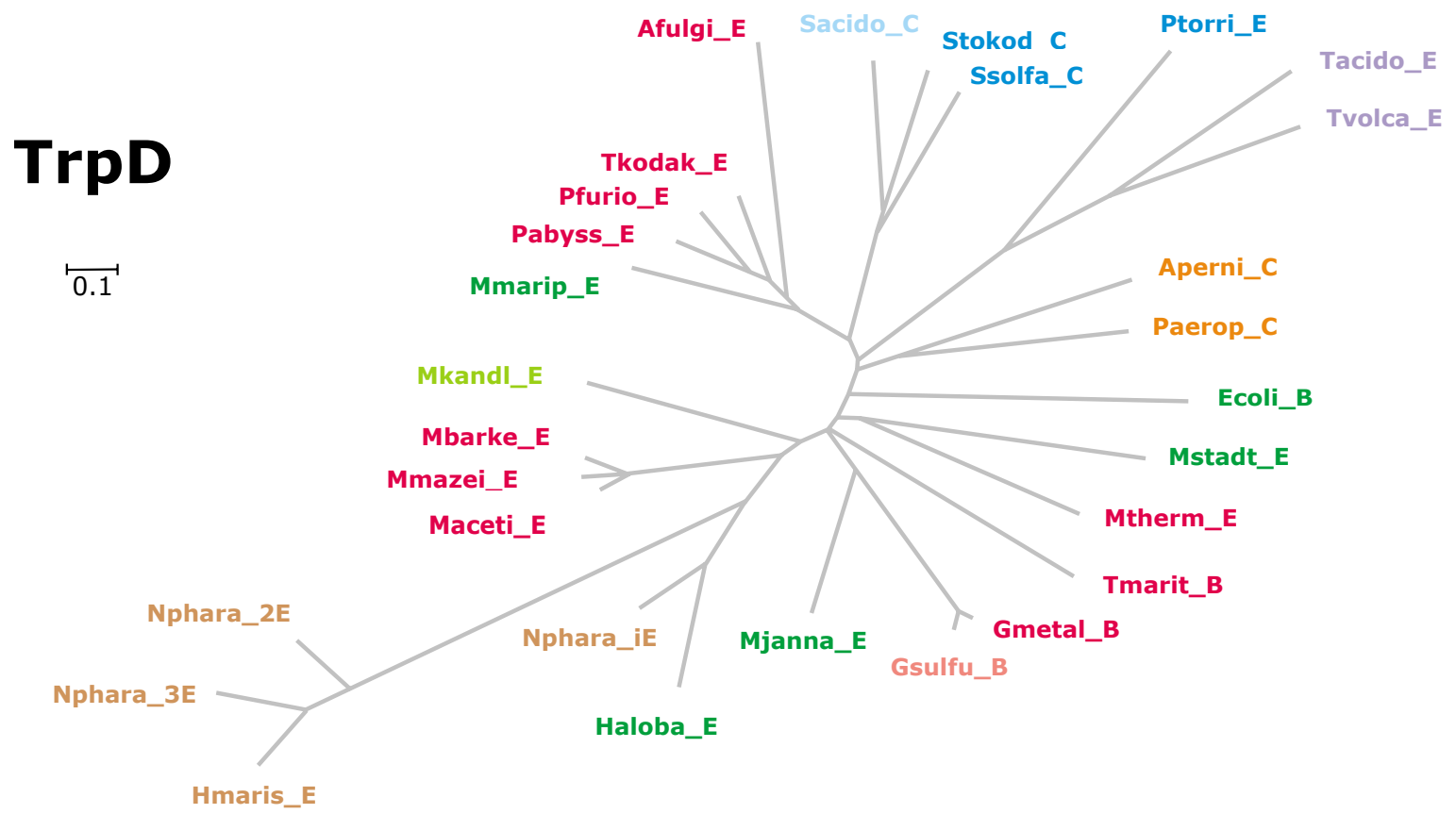

Figure 3

Phylogenetic tree of TrpD sequences. Archaeal and bacterial protein sequences were used to construct the unrooted tree. The last letter of the acronyms indicates the taxonomical position of the species. "E" marks Euryarchaeota, "C" Crenarchaeota, and "B" bacterial species. The three TrpD sequences of $N$. pharaonis are designated as _IE, _2E, and_3E. For colour code and abbreviations, see legend of Figure I.

evolutionary divergence is similarly high for several proteins encoded by the trp operon. These findings argue against a specifically increased rate of $\operatorname{trp} A$ and $\operatorname{trp} B$ evolution. In general, smaller genomes evolve faster [34]. Therefore, a higher evolutionary rate in the trp genes of Thermoplasmatales is more plausible explained by a general trend, which is due to their smaller genome size.

Interestingly, no sub-clustering into smaller, distinctly separated groups was observed in TrpE and TrpG, which form like $\operatorname{TrpA}$ and $\operatorname{TrpB}$ a heteromeric complex. The above finding distinguishes the subunits of tryptophan synthase from those of anthranilate synthase. TrpG was characterised as the evolutionary most stable trp protein by the compactness of its phylogenetic tree; see Figure 4.
The three Euryarchaeota Halobacterium (s1), Haloarcula marismortui (s1) and Natronomonas pharaonis (i1_s1 species) constituted an isolated group in all five trees (Figures $1,2,3,4)$; edge lengths were comparable to those of $s 2$ or i2_o2 species. This congruence indicates an elevated evolutionary rate for all elements of these trp operons. Note that these operons harbour $\operatorname{trpB} 1$ genes.

Analysing typical differences in TrpA and TrpB sequences The phylogenetic tree depicted in Figure 1 illustrates that all TrpB variants can be sorted into four, clearly separated groups. The tree did however not allow to deduce the degree of sequence similarity and to infer whether these differences were subtle sequence variations broadly distributed in the whole sequence or larger indels (inserts or deletions). Table 3 lists the results of pairwise sequence comparisons generated by using BLAST [35]. The selected 

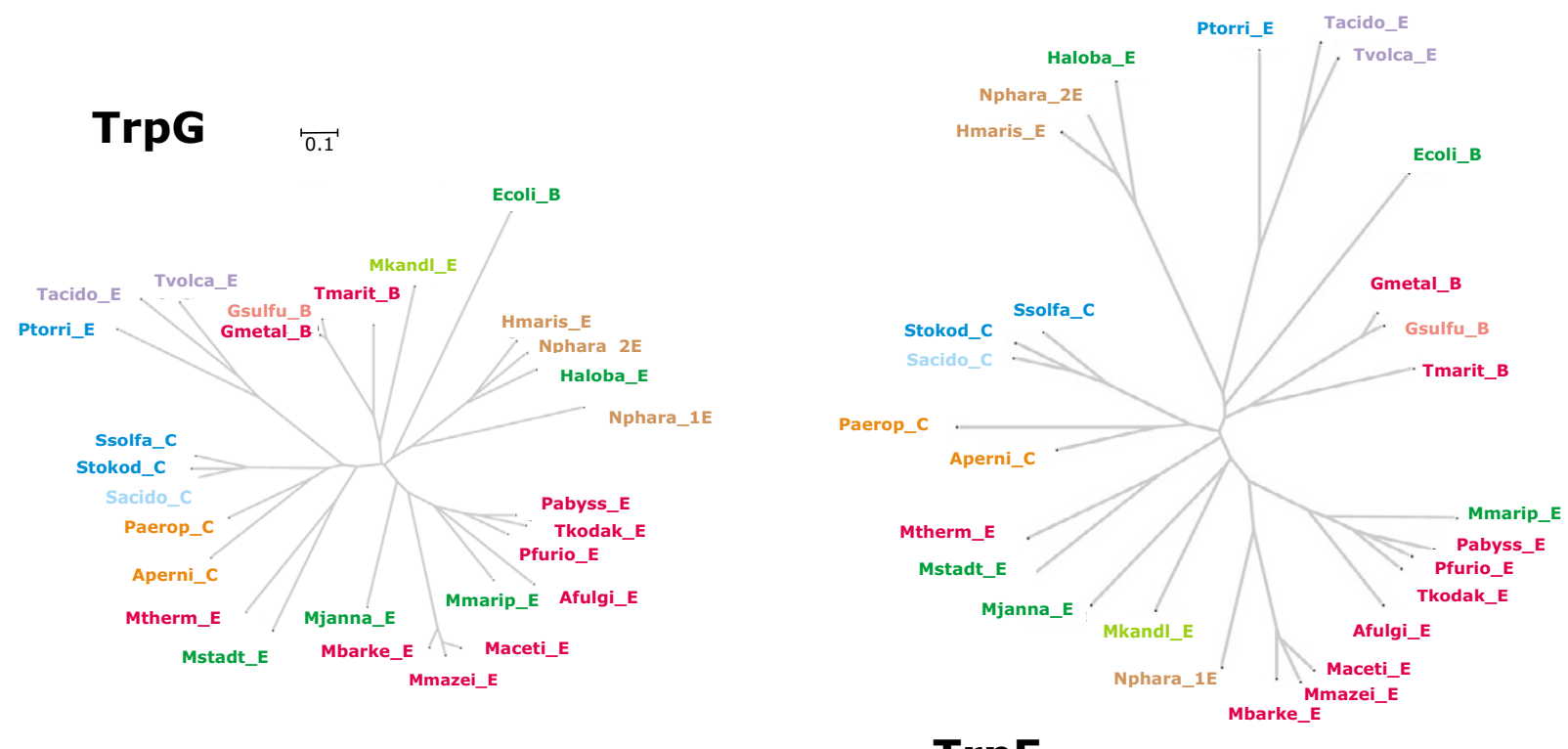

Figure 4

Phylogenetic trees for TrpG and TrpE sequences. Archaeal and bacterial protein sequences were used to construct the unrooted tree. The last letter of the acronyms indicates the taxonomical position of the species. "E" marks Euryarchaeota, "C" Crenarchaeota, and "B" bacterial species. The two TrpE sequences of N. pharaonis are designated as_IE,_2E. For colour code and abbreviations, see legend of Figure $I$.

sequences represent the species-types $S 2, i 2 \_02, i 1 \_02, s 1$, and $S 1$. As expected, sequence similarity values are in agreement with tree composition. Importantly, for all pairwise comparisons, more than $25 \%$ identical residues were determined. Therefore, all TrpB variants should most probably have the same overall 3D-structure [36].

In order to characterise sequence differences in detail, multiple sequence alignments (MSAs) were generated on the basis of a representative selection of $\operatorname{TrpA}$ and $\operatorname{TrpB}$ sequences. Figure 5 lists for TrpB the MSA, residue conservation, secondary structure and the location of the interface area. Residues interacting with ligands and residues, which are characteristic for TrpB1 and TrpB2 respectively, were labelled. 3D-data were deduced from the X-ray structure of Pfurio_i1E, i.e. the operon-based TrpB1 protein of $P$. furiosus [18], which has PDB code 1WDW. For Ssolfa_02C, the 2D-structure was predicted by using Jpred [37]. SDPpred [38] was employed to identify those residues, which separated $\operatorname{TrpB} 1$ and $\operatorname{TrpB} 2$ due to their skewed or bimodal distribution. In the following, positions and residues are referenced according to the sequence Pfurio_i1E. Annotations referring active site residues and the interface originate from the PDBsum page and the Macromolecular Structure Database of the EMBLEBI.

The MSA shows that nearly all differences between TrpB1 and $\operatorname{TrpB} 2$ are due to larger indels, in agreement with [25]. Interestingly, an insertion of 2 to 6 residues between positions 243 and 244 occurred coincidently in TrpB2_a and TrpB2_o sequences, i.e. exclusively in non operon-based proteins. All considered TrpB1 and TrpB2_i sequences lack this subsequence, which was not predicted as a welldefined 2D-element by Jpred. Several representatives belonging to these two sets of operon-based proteins were shown to interact with TrpA $[26,39]$. Therefore, it is probable that this putative loop influences the allosteric communication with TrpA. Most residues, which are in contact with ligands in the known $\operatorname{TrpB} 1$ structure, were strictly conserved among all $\operatorname{TrpB} 1$ and $\operatorname{TrpB} 2$ sequences. The only exception is residue C225, which is V225 in TrpB2_a sequences. The active site residues H81, K82, and S371 were strictly conserved, whereas active site residue K162 was conserved only in TrpB1 proteins and active site residue D300 (TrpB1) was an arginine in TrpB2. Several residues of the interface regions, adjacent to active sites and near sites interacting with ligands had a bimodal occurrence pattern distinguishing TrpB1 and TrpB2. 
Table 3: Pairwise sequence similarity values of TrpB proteins

\begin{tabular}{|c|c|c|c|c|c|c|c|c|c|c|c|}
\hline & Ssolfa_i2C & Ssolfa_o2C & Paerop_i2C & Paerop_o2C & Afulgi_ile & Afulgi_o2E & Tmarit_ilB & Tmarit_o2B & Mmarip_sIE & Mkand_SIE & Ecoli_sIB \\
\hline Tacido_S2E & $49,72,2$ & $76,88,0$ & $47,65,2$ & $46,67,1$ & $26,44,17$ & $46,64,2$ & $32,43,18$ & $47,66,2$ & $28,43,12$ & $30,46,11$ & $26,42,6$ \\
\hline Ssolfa_i2C & - & $54,75,2$ & $56,71,3$ & $53,72,1$ & $34,48,14$ & $57,72,1$ & $34,47,12$ & $54,73,1$ & $30,46,15$ & $30,45,12$ & $28,42,14$ \\
\hline Ssolfa_o2C & & - & $50,66,2$ & $52,71,1$ & $33,50,13$ & $47,68,1$ & $32,46,13$ & $48,70,1$ & $28,43,16$ & $30,45,11$ & $27,40,10$ \\
\hline Paerop_i2C & & & - & $57,68,3$ & $35,49,14$ & $54,63,3$ & $35,50,12$ & $54,65,3$ & $32,48,12$ & $34,46,15$ & $31,43,13$ \\
\hline Paerop_o2C & & & & - & $30,45,13$ & $63,78,1$ & $32,46,13$ & $60,75,1$ & $28,44,16$ & $33,46,11$ & $28,41,16$ \\
\hline Afulgi_ilE & & & & & - & $31,44,11$ & $65,78,0$ & $36,48,10$ & $65,85,0$ & $65,78,0$ & $59,76,1$ \\
\hline Afulgi_o2E & & & & & & - & $34,47,12$ & $64,76,0$ & $30,45,9$ & $32,45,9$ & $29,40,12$ \\
\hline Tmarit_ilB & & & & & & & - & $35,47,11$ & $61,79,1$ & $64,79,1$ & $58,75, I$ \\
\hline Tmarit_o2B & & & & & & & & - & $34,46,9$ & $32,46,8$ & $29,40,12$ \\
\hline Mmarip_sIE & & & & & & & & & - & $59,77,0$ & $58,77,0$ \\
\hline Mkand_SIE & & & & & & & & & & - & $57,72,0$ \\
\hline
\end{tabular}

Note: The sequences represent species-types S2, i2_o2, il_o2, sI, and SI. All pairs were compared by using BLAST with default parameters. For each pair, the fraction of identical residues, similar residues, and inserted gaps is given in percent. For the generation of protein names, see Results.

Among these were residues 2 and 110, which were strictly conserved tryptophan residues in all TrpB2 proteins. Given its position near the gene start, W2 may assume a function in translation control. W110 succeeds a cluster of strictly conserved residues suggesting a role in stability or protein function.

Figure 6 lists the MSA generated for TrpA sequences. It shows that the active site residues E36, D47, and Y161 are strictly conserved in the TrpA sequences studied. Most evident was a three-residue insertion into TrpA2 sequences following position 125 (numbering deduced from TrpA of $P$. furiosus) as well as deletions at position 162 and between positions 172 and 174. Moreover, most positions showing a bimodal or skewed distribution specific for a $\operatorname{trp} A$ variant were located near interface regions. In summary, the deviations characterising the two TrpA variants were not as pronounced as those observed in TrpB sequences, however three indels distinguished $\operatorname{TrpA} 1$ from TrpA2.

\section{Frequency of Trp codons in trpB genes}

It has been postulated that the avoidance of tryptophan residues in enzymes for tryptophan synthesis provides a selective advantage [7] as has been shown for a number of amino acid biosynthetic enzymes [40]. This criterion was also applied to the $\operatorname{trp} B$ genes by assessing the frequency of tryptophan codons (Table 2). $\operatorname{trpB1}$ genes contained one or two tryptophan codons with a mean value of 1.6 both for $S 1, s 1$, and $i 1 \_o 2$ species. $\operatorname{trpB2}$ genes contained two tryptophan codons or more with a mean of 2.75 for S2 species, and 3.0 for $i 2 \_02$ species. Most pronounced was the difference for $i 1 \_02$ species. Here, $\operatorname{trp} B 2$ genes had a mean of 3.7, whereas $\operatorname{trpB1}$ genes had a mean of 1.6 tryptophan codons. These $\operatorname{tr} p B 1$ genes showed a habitat-specific imbalance of tryptophan codon occurrence with one in mesophilic species and at least two tryptophan codons in hyperthermophiles. In summary and according to the notion of tryptophan codon avoidance, $\operatorname{trpB2}$ genes are less optimised than $\operatorname{trp} B 1$ genes.

\section{The composition of archaeal trp gene clusters}

The evolution of individual genes and operon formation proceed in parallel. For the combined analysis of both processes, gene orders of relevant archaeal and some bacterial trp operons were determined and plotted in Figure 7. In most operons, the gene orders $\operatorname{trp} B A$ and $\operatorname{trp} E G$, respectively, were conserved; however, the arrangement of the linkage groups varied. Figure 7 is organised as six panels A - F. Panel A depicts the trp clusters of Thermoplasmataceae, which are of type $\operatorname{trpA2DFEGC;} \operatorname{trpB2}$ lies isolated. In Sulfolobaceae and P. torridus (Panel B), trpB2 is

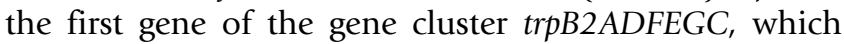
matches the above trpA2DFEGC in all positions following trpB2. Panel $C$ gives the gene clusters of $A$. pernix and $P$. aerophilum, which possess a $\operatorname{trpB} 2 \_i$ and a $\operatorname{trpB2} \_o$ gene. In the genome of $A$. pernix, two linkage groups $\operatorname{trp} A 2 B 2 F C$ and trpDEG occur; $P$. aerophilum possesses the cluster $\operatorname{trpB2DEGA2.~Panel~D~lists~archaeal~genomes~containing~}$ linkage groups $\operatorname{trpCB} 1 A 1$ and $\operatorname{trpDFEG}$. In Methanosarcina mazei, these genes form a single cluster, resulting in trpCB1A1DFEG. In N. pharaonis, these groups are separated by more than $69 \mathrm{~kb}$. In panel $\mathrm{E}$, operons are listed where trpB1 lies close to the 3'-terminal end. For Thermococcus kodakaraensis, Methanococcus maripaludis, Archaeoglobus fulgidus and Pyrococcus abyssi, gene order is trpCDEGFB1A1. The gene orders in Panel E resemble bacterial operons; two representative examples are plotted in panel F.

It has been argued that simple trp clusters may have been unstable until the complexity of regulation and the foundation of a metabolic theme had reached a certain level [10]. Gene clusters observed in $s 2$ and i2_o2 species can be considered the less evolved stages of cluster organisation; compare Panels A - C. Moreover, the only archaeal trp gene regulatory systems identified so far are part of the trp operons of $M$. thermoautotrophicus [7] and T. kodakaraensis [8], which both have a bacterial-like composition. 


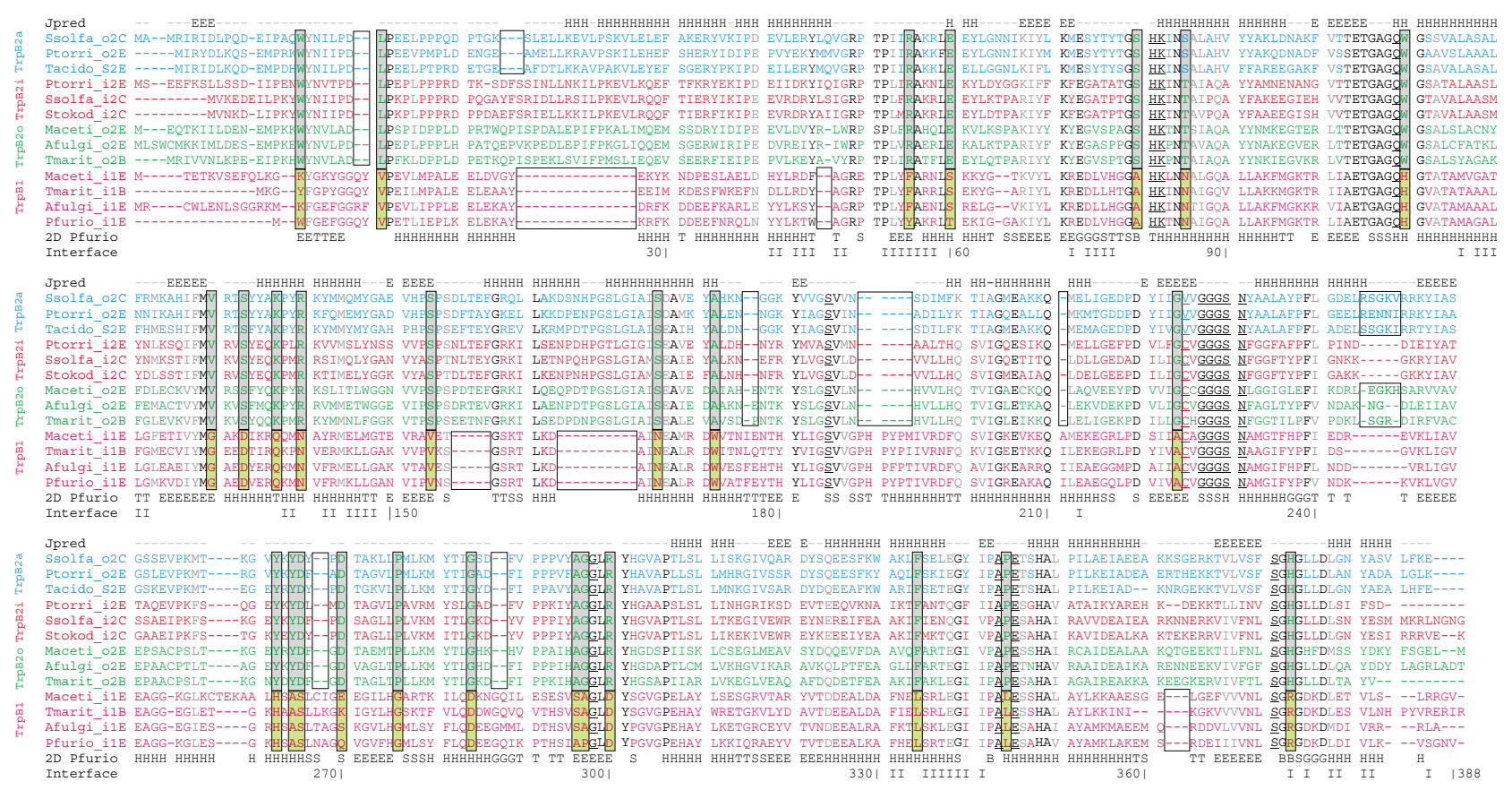

\section{Figure 5}

Multiple sequence alignment of TrpB sequences. Representatives of the four groups of TrpB sequences were aligned. Ssolfa_o2C, Ptorri_o2E, and Tacido_S2E represent TrpB2_a sequences. Ptorri_i2E, Ssolfa_i2C, and Stokod_i2C represent TrpB2_i, Maceti_o2E, Afulgi_o2E, and Tmarit_o2B represent TrpB2_o sequences. Maceti_ilE, Tmarit_ilB, Afulgi_ilE, and Pfurio_ilE represent TrpBI sequences. The 2D-structural elements of Pfurio_ilE, as deduced from the PDB file IWDW, are shown below the sequences, and residues involved in protein interaction with TrpA (I) are assigned under 'Interface'. The line Jpred (top) lists a 2D-prediction of Ssolfa_o2C generated by using the Jpred server [37]. Residues in bold face printing are conserved; black residues are strictly, grey residues are less strictly conserved. Active site residues are plotted in italics; residues in contact with ligands are underlined. These data were deduced from the PDBsum pages [56] and the PISA server [58] of the EMBL-EBI. Residues printed in boxes were predicted by SDPpred [38] as being specific for TrpBI or TrpB2. See legend of Figure I for an explanation of sequence acronyms.

Besides Nanoarchaeum equitans, Thermoplasmata (T. volcanium, T. acidophilum, and P. torridus) possess the smallest archaeal genomes sequenced so far. Most plausibly, strong selective pressure associated with the colonised habitat enforces the minimisation of genome size. However, both Thermoplasma species possess the gene cluster

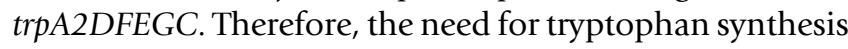
can be taken for granted. The separation of $\operatorname{trp} B 2$ from the remaining trp genes is consistent with a demand for individual gene regulation and expression presumably due to an additional function of TrpB2. Most plausibly, under these constraints, $\operatorname{trp} B 2$ is the more optimal variant, which is in a specific environment favoured over $\operatorname{trp} B 1$.

\section{What is the origin of trpB genes?}

Recently, TrpA, Tmari_i1B and Tmari_o2B of T. maritima have been produced in E. coli, purified, and characterised [39]. It has been shown that recombinant TrpA forms an $\alpha$-monomer, and that both recombinant $\operatorname{TrpB}$ proteins form $\beta_{2}$-homodimers. However, only the operon- encoded Tmari_i1B - but not Tmari_o2B - associated with TrpA to constitute the conventional $\alpha \beta \beta \alpha$ tryptophan synthase complex in which both subunits reciprocally activate each other. An analogous experiment has been carried out for genes of $S$. solfataricus [26]. The results have shown that Ssolfa_i2C - but not Ssolfa_o2C - associates transiently with TrpA during catalysis to form a functional tryptophan synthase complex. However, in contrast to regular tryptophan synthases, the affinity between the two subunit-types was weak, and activation has been unidirectional from Ssulfo_i2C to TrpA. These results indicate the following ranking for the bindingaffinity to TrpA: TrpB2_o $<\operatorname{TrpB} 2 \_\mathrm{i}<\operatorname{TrpB} 1$.

In the course of modelling $\operatorname{trp} B$ evolution, the relationship between the $\operatorname{tr} p B$ variants has to be made plausible. A possible explanation for the existence of two $\operatorname{trp} B$ variants would be convergent evolution, i.e. the independent development of $\operatorname{trpB} 1$ and $\operatorname{trp} B 2$ towards a $\operatorname{trp} B$ gene. In this case, few residues, which are critical for function, 


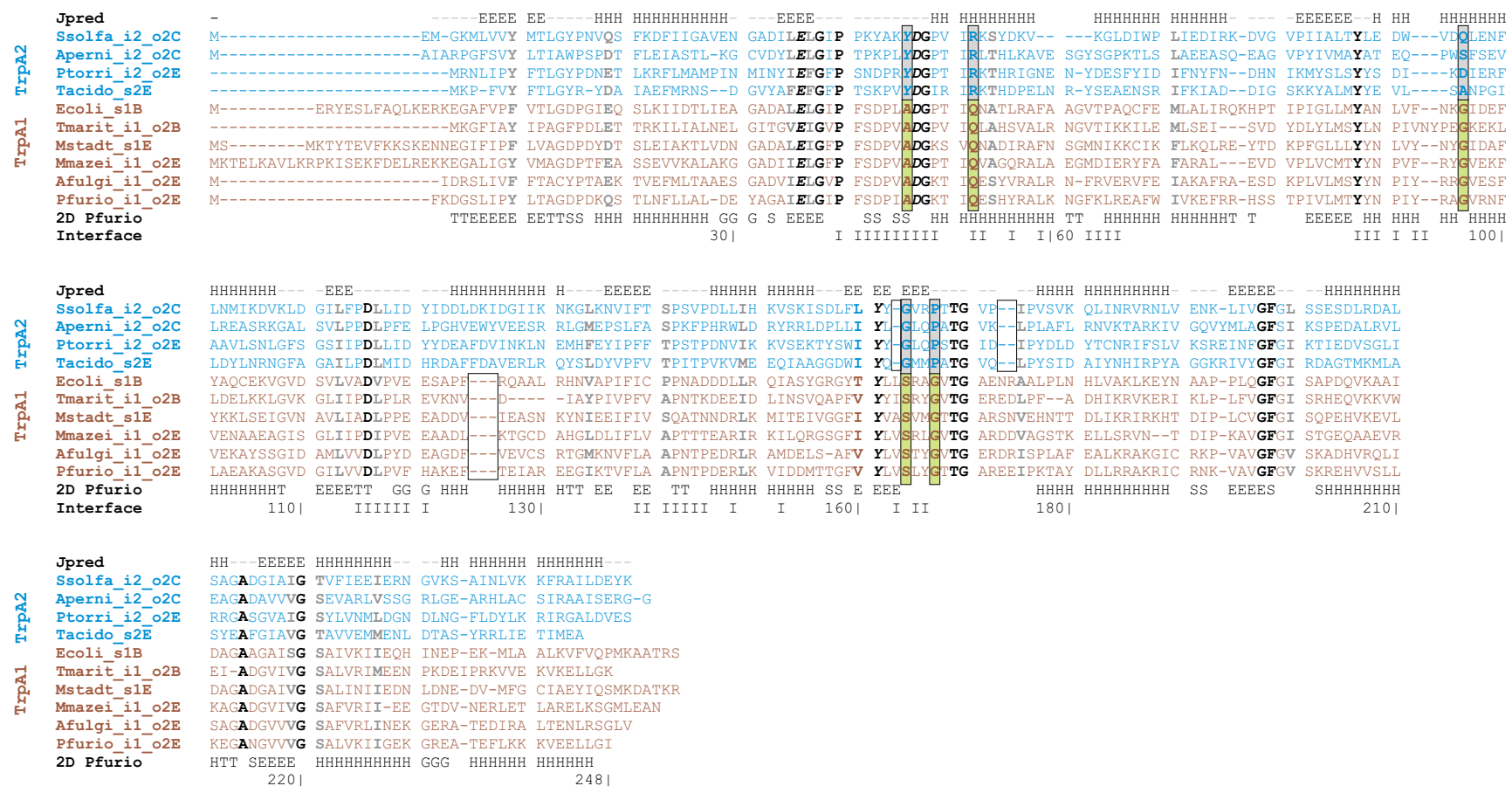

Figure 6

Multiple sequence alignment of TrpA sequences. Ssolfa_i2_o2C, Aperni_i2_o2C, and Ptorri_i2_o2C represent TrpA sequences from i2_o2 species possessing both an operon-based and a non operon-based trpB2. Tacido_s2E represents a species having exclusively an operon-based trpB2. Ecoli_sIB and Tmarit_il_o2B represent bacterial TrpA proteins. Mstadt_sIE is from a species possessing exclusively an operon-based trpBI gene, Mmazei_il_o2E, Afulgi_il_o2E and Pfurio_il_o2E are TrpA sequences from $i l \_02$ species possessing an operon-based $\operatorname{trp} B I$ and a non operon-based $\operatorname{trp} \bar{B} 2$ gene. Presumably, these TrpAI proteins interact with a protein of type TrpBI. Below the alignment, the 2D-structure of TrpA of $P$. furiosus (Pfurio_il_o2E), and residues involved in protein interaction with its $\operatorname{TrpBI}(\mathrm{I})$ are given. The line named Jpred lists a 2D-prediction of Ssolfa_i2_o2C generated by using the Jpred server [37]. Residues printed in bold are conserved; black residues are strictly, grey residues are less strictly conserved. Active site residues are plotted in italics. These data were deduced from the PDBsum pages [56] and the PISA server [58] of the EBI. Residues printed in boxes were predicted by SDPpred [38] as being specific for the two TrpA species.

should correspond. However, one would expect these residues embedded into polypeptides, which are relatively dissimilar on the sequence level. In contrast, comparison of TrpB1 and TrpB2 sequences shows that on average $30 \%$ of the residues are identical and $40 \%$ are similar; compare Table 3. This finding and the conservation of indels makes convergent evolution highly improbable and argues for a common origin of $\operatorname{trpB} 1$ and $\operatorname{trpB} 2$ genes.

The most-widely accepted model for the evolution of novel protein functions postulates gene duplication and the generation of a redundant gene copy [41]. It is assumed that evolutionary stress for a copy is largely reduced thus facilitating the evolution of a paralogue with a novel function. This model is based on the notion that negative trade-offs dominate evolutionary processes [42]. According to this model of evolution, one of the $\operatorname{trp} B$ genes originates from a copy of the ancestral variant.
Which of the two existing variants represents the more ancient gene? The arguments listed below suggest that $\operatorname{trpB2}$ is the ancestral $\operatorname{trpB}$ gene.

i) $\operatorname{trpB1}$ is not universally distributed among archaea. Crenarchaeota possess exclusively $\operatorname{trpB2}$ genes. ii) A low frequency of amino acids in enzymes required for their synthesis provides selective advantage [40]. In general, $\operatorname{trpB1}$ genes contain fewer tryptophan codons than $\operatorname{trpB2}$ genes; in $11 \_02$ species, the ratio is $1.6 / 3.7$ i.e. less than 0.5 . Therefore, $\operatorname{trpB} 1$ is the more evolved gene. iii) The sophisticated inter-subunit communication suggests that the products of $\operatorname{trp} B 1$ and $\operatorname{trp} A 1$ of species-types $s 1$ or $i 1 \_o 2$ are the most efficient enzymes; see [39] and references therein. Hence, $\operatorname{TrpB} 1$ is the more optimised and later evolved TrpB variant. iv) It has been postulated that ancient enzymes possess broad specificities [43]. The occurrence of $\operatorname{trpB2}$ outside trp operons argues for either a 


Panel
Species

\section{Figure 7}

Gene organisation of archaeal and bacterial trp gene clusters. Each panel A - F represents the occurrence and orientation of trp genes in the genomes of organisms listed in the second column. The third column gives the species-type and the taxonomical lineage. "E" marks Euryarchaeota, "C" Crenarchaeota, and "B" bacteria. A vertical double line (Panels A and D) indicates borders of gene clusters separately located in the genome. Open arrows represent hypothetical genes. The arrows are not to scale; gaps of arbitrary length were inserted between genes to allow the alignment of arrows. For acronyms of speciestypes, see legend of Table 2.

new function or a broader specificity. In summary, it is plausible to regard $\operatorname{trp} B 2$ as representing the more ancient variant of $\operatorname{trp} B$.

\section{Modelling the evolution of TrpB}

In order to reduce the number of possible alternative scenarios that have to be discussed for modelling the evolution of $\operatorname{trpB}$, the following assumptions were made:

i) For bacteria, an ancestral trp operon of type trpEGDCFB1A1 is most likely [10]. Therefore, the existence of a trpB1 gene in the bacterial predecessor was taken for granted. In addition, it has been concluded for bacterial trp operons that horizontal gene transfer (HGT) did not affect the path of evolutionary history [44].

ii) $\operatorname{trp} B 1, \operatorname{trp} B 2, \operatorname{trp} A 1$ and $\operatorname{trp} A 2$ have been invented only once. The analysis of multiple sequence alignments (see Figures 5 and 6) shows that the main differences distinguishing the variants are conserved indels. It has been convincingly argued that conserved indels result less likely than e.g. point mutations from independent mutational events and provide useful milestones for the identification of evolutionary phases [45]. In addition, the strong coherence seen in the TrpB subtree argues against an independ- ent evolution occurring in parallel for bacteria and archaea. Due to the existence of conserved indels, an evolutionary process $\operatorname{trpB2} i \rightarrow \operatorname{trpB} 1 \rightarrow \operatorname{trpB2} \_o$ or vice versa is unlikely too.

iii) As has been deduced previously [46], the following order of importance was taken for the processes of genome evolution: gene loss > gene genesis > gene duplication > HGT.

$i v$ ) The integration of a $\operatorname{trp} B$ gene into the trp operon (or linkage group) was rated less probable than other translocations, gene duplications, gene loss, and mutations. It is presumably very rare that a particular gene gets integrated into a specific gene cluster [47], which is the trp operon in the considered case.

$v$ ) It is unlikely that several recent events of HGT explain the taxonomically widespread occurrence of $\operatorname{tr} p B 2$ genes in bacteria. In bacteria, $\operatorname{trpB2}$ genes were found in hyperthermophilic (Aquificae and Thermotogae) and mesophilic bacteria belonging to the taxonomical groups of Alphaand Gammaproteobacteria and Bacteroides. The program SIGI [48] identifies genomic islands, i.e. gene clusters having a conspicuous codon usage indicating recent HGT 


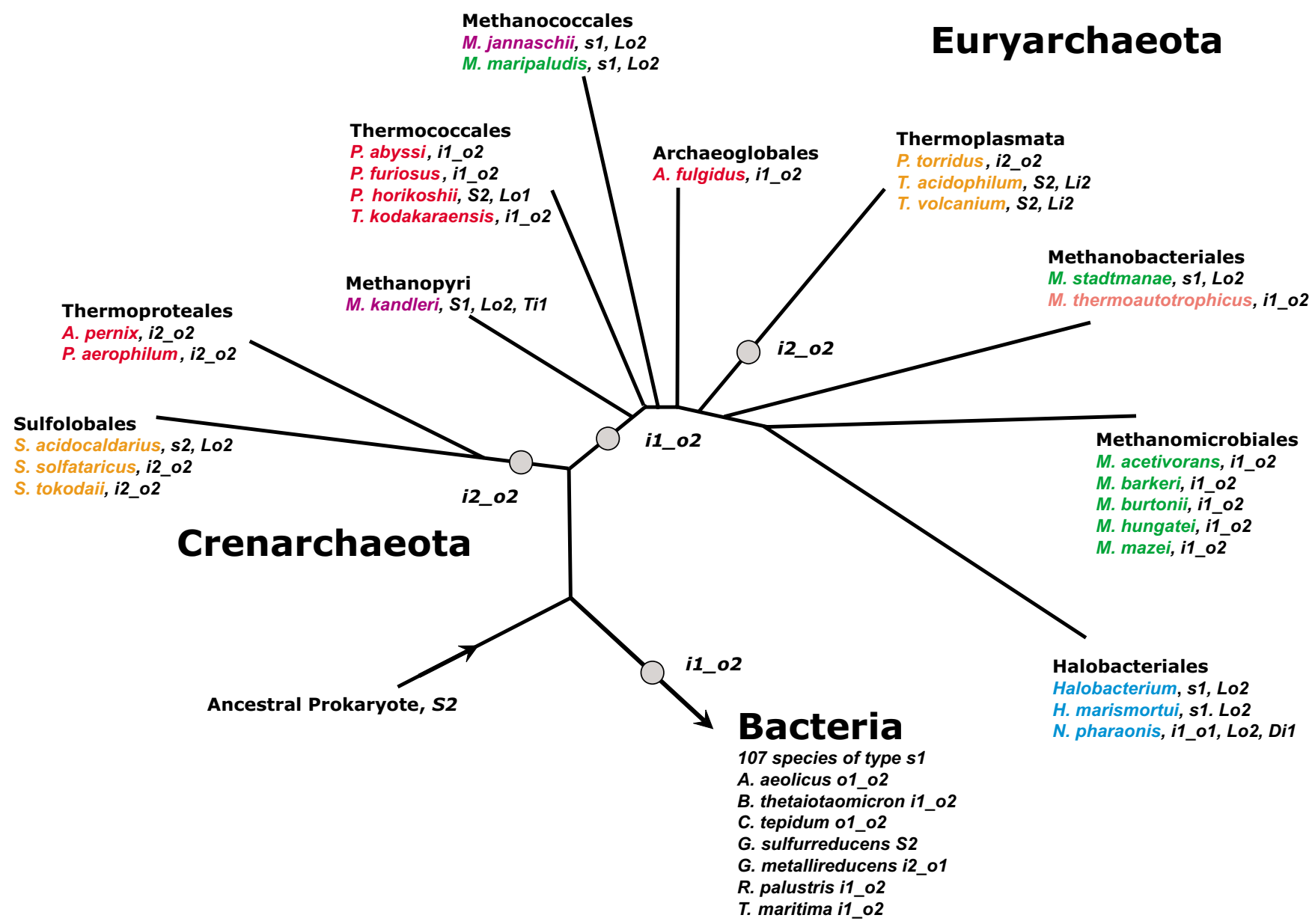

Figure 8

A parsimonious reconstruction of predecessors. The phylogenetic tree is based on I6S rRNA sequence comparisons (after Fig. 2 of [49]). For all modern species, their species-type and evolutionary events leading most plausibly from the ancestral predecessor to the current genome content are added. The most probable species-type of predecessors for Crenarchaeota, Euryarchaeota, and Bacteria is given next to the grey circles. Abbreviations for events changing genomic content: Lil or Lo2, (L)oss of the operon-based trpBI or the non operon-based trpB2 gene, respectively. Til (T)ranslocation of the operon based $\operatorname{trpBI}$, Dil (D)uplication of the operon-based trpBI. The colour of species names indicates the habitat: Hyperthermophiles are given in red, thermoacidophiles in orange, thermophiles in pink, mesophiles in green, halophiles in blue, and species living in a both hyperthermophilic and halophilic environment are given in purple.

events. In none of the considered genomes were $\operatorname{trpB} 1$ or trpB2 genes (both inside and outside operons) elements of such islands.

In order to model the evolution of tryptophan synthase, a phylogenetic tree based on archaeal 16S rRNA sequence comparisons was plotted according to Fig. 2 from [49]. All considered species and their species-types were added. Using the above premises, the most plausible sequencetypes of predecessors were determined. These types and evolutionary events needed to infer the modern species- types from the predecessors were added to the tree; see Figure 8.

The most plausible predecessor of all Crenarchaeota is of type i2_o2; for Bacteria and for Euryarchaeota it is of type i1_o2. Assuming this and excluding Thermoplasmata (see below), of the 23 modern archaeal species, 14 have the same species-type as their ancestor. Of the 9 species possessing a deviating type, 7 can be explained with a single gene loss, and for only 2 modern species a more complicated genomic rearrangement has to be postulated: Loss of $\operatorname{trpB2}$ and dislocation of $\operatorname{trpB1}$ has to be postulated for 


\section{Archaea}

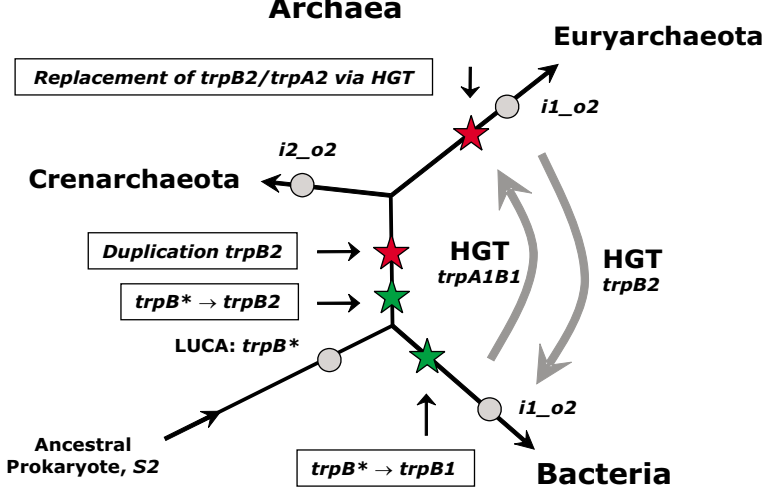

B

Archaea

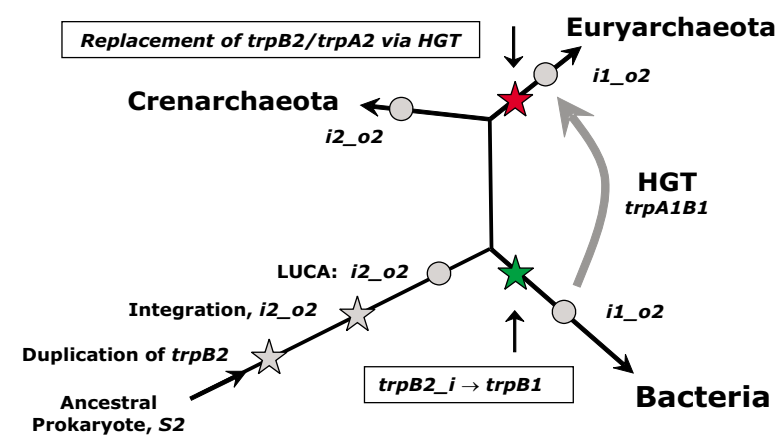

Archaea

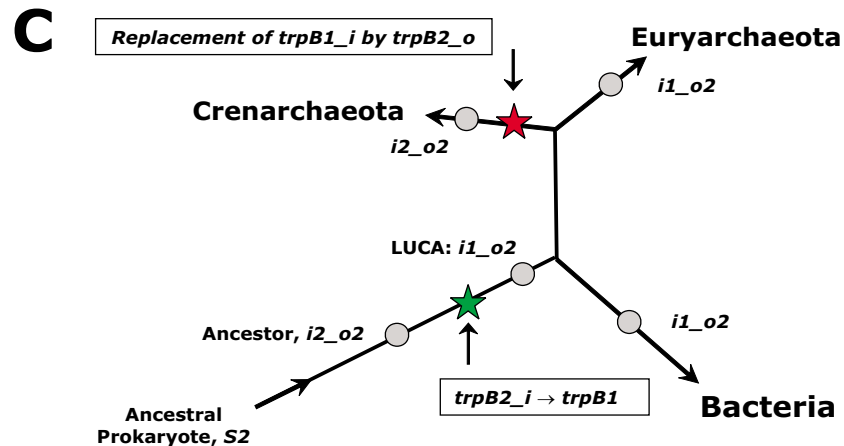

Figure 9

Alternative models of $\operatorname{trp} B$ evolution. Model $A$ assumes that a single and intermediate $\operatorname{trp} B^{*}$ gene existed in the last universal common ancestor (LUCA) of bacteria and archaea. The evolution of the $\operatorname{trpB2}$ gene is considered an archaeal and that of the $\operatorname{trp} B /$ gene is considered a bacterial invention. The occurrence of $\operatorname{trp} A I$ and $\operatorname{trp} B I$ genes in archaea and of $\operatorname{trp} B 2$ genes in bacteria are explained by a twofold horizontal gene transfer (HGT). A duplication of trpB2 in an ancient archaeal genome has been postulated to explain the existence of the non operon-based trpB2. Models $B$ and $C$ propose two alternatives for the evolution of the LUCA. Model B assumes that the evolution $\operatorname{trp} B 2 \rightarrow \operatorname{trp} B /$ occurred in an early bacterial species after the divergence of bacteria and archaea. The replacement of linkage group trpB2A2 by trpBIAI via HGT was postulated to account for the euryarchaeal predecessor of type il_o2. Model $C$ assumes that the evolution $\operatorname{trp} B 2 \rightarrow \operatorname{trp} B I$ occurred before the divergence of bacteria and archaea. Hence, the replacement of an operon-based trpBI by a trpB2 gene and the evolution $\operatorname{trp} A I \rightarrow$ $\operatorname{trp} A 2$ was postulated for the crenarchaeal ancestor. For acronyms of species-types, see legend of Table 2. Distances are arbitrary and do not represent evolutionary time intervals. Stars indicate events of genomic rearrangements, circles filled in grey represent ancient predecessors. 


\section{Archaea}

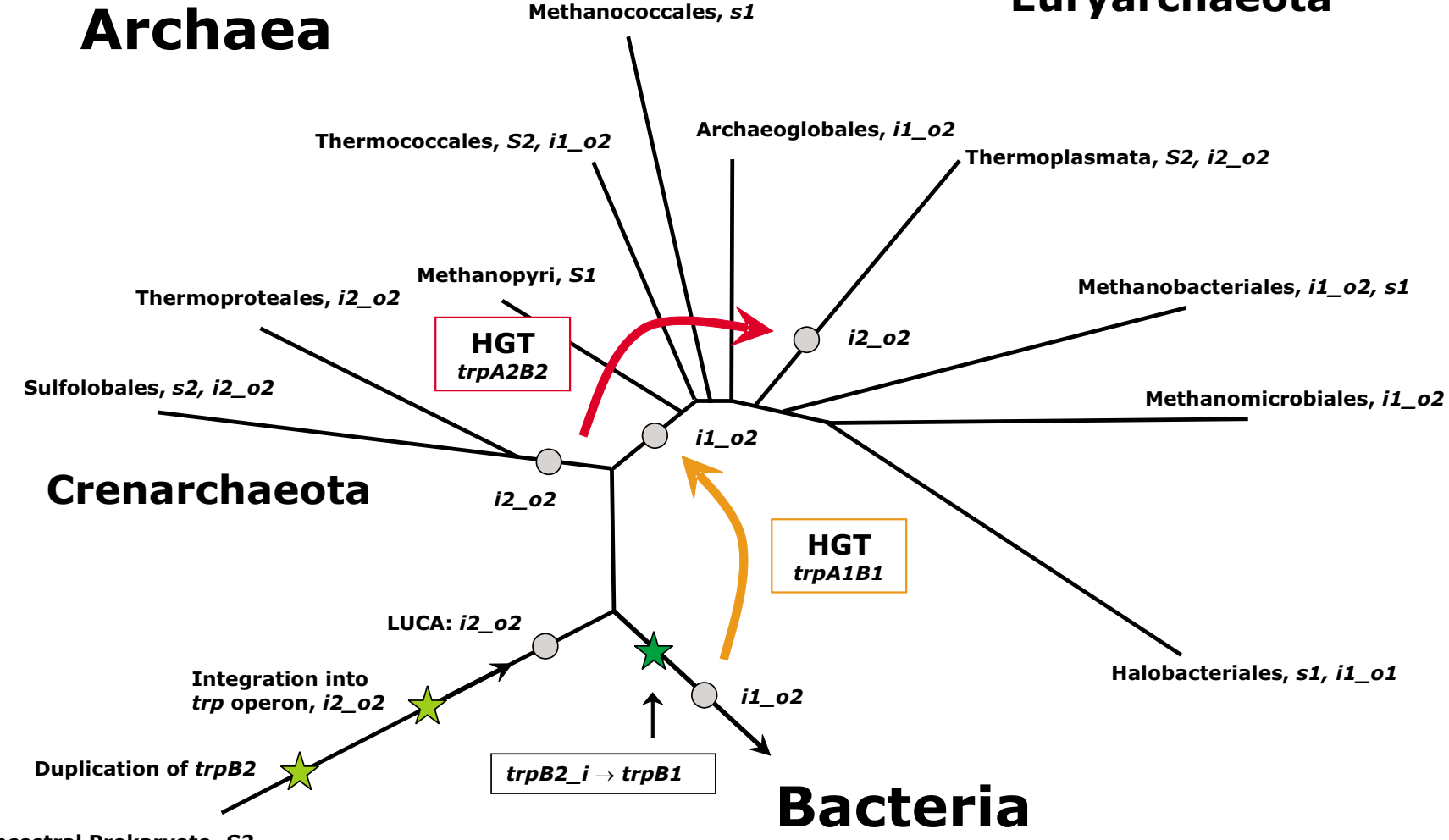

Ancestral Prokaryote, S2

Figure 10

Composite model of trpB evolution. Upon duplication and integration of an ancient trpB2 gene into the trp operon, the last universal common ancestor (LUCA) of bacteria and archaea was of species-type i2_02. In a bacterial ancestor, the evolution of a linkage group trpBIAI occurred. Via horizontal gene transfer (HGT), an euryarchaeal ancestor acquired this linkage group, which gave rise to a predecessor of type il_o2. Thermoplasmata acquired trpA2 and trpB2 genes in an ancient event of HGT. For all taxonomical orders, species-types of current species are given. S2 species possess exactly one, non operon-based $\operatorname{trpB2}$ gene, s2: ditto, the gene is located inside the $\operatorname{trp}$ operon. $\operatorname{trpBI}$ was treated analogously. i2_o2 are species possessing a $\operatorname{trp} B 2$ gene inside and a second $\operatorname{trp} B 2$ outside the operon, $i l \_02$ are species with an operon-based trpBI and a non operonbased $\operatorname{tr} B 2$, and $i l \_o l$ are species possessing an operon-based and at least one non operon-based $\operatorname{trp} B I$.

M. kandleri (representing Methanopyri), which is a $S 1$ species. The replacement of $\operatorname{trpB} 2 \_o$ with a copy of $\operatorname{trpB} 1$ is necessary to explain the $i 1 \_01$ genome of $N$. pharaonis. The only euryarchaeal class requiring a more complex explanation than gene loss and translocation subsumes Thermoplasmata, which possess exclusively $\operatorname{trpB2}$ and $\operatorname{trp} A 2$ genes. The composition of congruency groups (compare Figures 1 and 2) makes a common evolution with Sulfolobales or the acquisition of the same trp genes probable. The similarity of operon structures supports this assumption: operon structures of $P$. torridus and Sulfolobales are identical (compare Panel B of Figure 7). For T. acidophilum, a large amount of HGT with $S$. solfataricus, which is found in the same habitat, has been made plausible [50]. In summary, a common evolutionary history of $\operatorname{trpB2}$ and trpA2 genes of Sulfolobales and Thermoplasmata is highly plausible, proposing for both taxonomical classes an ancestor of species-type $i 2 \_02$. Assuming an $i 2 \_02$ ances- tor, gene loss is sufficient to explain the genome composition of all modern Thermoplasmata.

Based on these predecessors, three alternatives explaining the evolution and distribution of $\operatorname{tr} p B$ species starting from the last universal common ancestor (LUCA) of bacteria and archaea were deduced (Figure 9, Panels A - C). In the following paragraph, the plausibility of these alternatives will be discussed. The rest of this paragraph is used to elucidate the three alternatives.

In Panel A of Figure 9, the existence of an ancestral $\operatorname{tr} p B^{*}$, an intermediate of $\operatorname{trp} B 1$ and $\operatorname{trp} B 2$ was postulated for the LUCA. $\operatorname{tr} p B^{*}$ might then have diverged into a bacterial $\operatorname{trpB1}$ and an archaeal $\operatorname{tr} p B 2$ variant. To explain the existence of a non operon-based $\operatorname{trpB2}$ in archaea, a duplication of $\operatorname{trpB2}$ is necessary. The advent of an euryarchaeal i1_o2 predecessor requires the replacement of linkage 
group $\operatorname{trp} B 2 A 2$ with $\operatorname{trpB1A1}$ via HGT from bacteria to archaea. The occurrence of $\operatorname{trpB2}$ in bacterial genomes demands an early transfer of $\operatorname{tr} p B 2$ from an archaeal to a bacterial predecessor.

Panel B of Figure 9 depicts an alternative model for the evolution of the LUCA towards the bacterial and archaeal ancestors. As introduced above, gene duplication is regarded the first step for evolving a novel gene function. In addition, $\operatorname{trp} B 2$ must be considered to represent the more ancient variant of $\operatorname{tr} p B$. Therefore, the evolution towards the LUCA of bacteria and archaea is most plausibly explained by the duplication of a non operon-based $\operatorname{trpB2}$ gene, which was subsequently integrated into the trp operon and constituted an ancient linkage group $\operatorname{trpB2A2.}$ This makes a common ancestor of type i2_o2 plausible. These considerations are the basis for further reconstructing the evolution of predecessors. In Panels B and C, two alternatives are given.

In Panel B, it is assumed that the LUCA was of type i2_o2 and that the evolution $\operatorname{trpB2} \rightarrow \operatorname{trpB} 1$ occurred in an early bacterial species. In this case, species-types of the LUCA and the crenarchaeal predecessor are identical. To explain the advent of an euryarchaeal predecessor of type i1_o2, an ancient event of HGT from Bacteria to Archaea has to be postulated for the acquisition of the linkage group

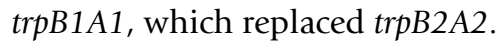

In Panel C, it is assumed that the LUCA was of type i1_o2, i.e. the evolution $\operatorname{trpB2} \rightarrow \operatorname{trpB} 1$ occurred earlier than the speciation of Bacteria and Archaea. In this case, the speciestypes of the LUCA and the predecessors of Bacteria and Euryarchaeota are identical. However, a replacement of $\operatorname{trpB2} \_i$ by $\operatorname{trpB2} \_o$ is necessary to constitute the crenarchaeal predecessor.

\section{How plausible are these three models?}

Model A requires at least two ancient events of HGT to explain the occurrence of $\operatorname{trp} B 2$ in Bacteria and of $\operatorname{trp} A 1 B 1$ in Euryarchaeota. The phenomenon of non-orthologous displacement in situ is well-characterised [51,52]. In addition to HGT, a duplication of the $\operatorname{trpB2}$ gene is needed for the predecessor of Archaea. This model is not the most parsimonious one: Model B demands only one HGT event, the ancient acquisition of the linkage group $\operatorname{trpB1A1}$ by an euryarchaeal predecessor.

Model C postulates a LUCA of species-type i1_o2. The sophisticated inter-subunit communication clearly suggests that products of $\operatorname{trpB} 1$ and $\operatorname{trp} A 1$ genes are the most specialised and most recently evolved tryptophan synthases; see [39] and references therein. Thus, the replacement of $\operatorname{trpB1}$ with $\operatorname{trpB2}$, which is needed to explain the existence of a crenarchaeal predecessor of type i2_o2, would - with respect to protein-protein interaction - lead to a less optimal tryptophan synthase. This seems unlikely, if one presumes the sustained need for tryptophan synthesis in Crenarchaeota.

In contrast, model B postulates the replacement of a (less evolved) $\operatorname{trpB2} i$ by a $\operatorname{trpB} 1$ for the euryarchaeal predecessor and does not require the replacement of a $\operatorname{trpB1}$ by a $\operatorname{trpB} 2$ for the crenarchaeal predecessor. The case of Thermoplasmata makes clear that in a thermophilic or hyperthermophilic environment $\operatorname{trp} B 2$ and $\operatorname{trp} A 2$ genes are favoured over $\operatorname{trpB1}$ and $\operatorname{trpA1}$. There is evidence that the LUCA was a thermophilic or hyperthermophilic species $[34,53,54]$. Therefore, it is more probable to expect a LUCA of speciestype $22_{-} 02$. In summary, considering parsimony arguments and the assumption that negative trade-offs dominate evolutionary processes [42], model B is the likelier one. Figure 10 summarises the most parsimonious scenario explaining the composition of modern archaeal trp operons: Assuming that the LUCA was of type i2_o2, and that $\operatorname{trpB1}$ was a bacterial invention, besides gene loss, which is a frequent evolutionary event, two cases of ancient HGT are sufficient to explain the distribution of $\operatorname{trp} A$ and $\operatorname{trp} B$ species in current archaeal genomes.

\section{Conclusion}

In archaeal genomes, various stages of $\operatorname{trp} B$ function have been conserved. Most plausibly, $\operatorname{trpB2}$ represents the ancestral variant of $\operatorname{trp} B$ genes. With respect to $\operatorname{Trp} A / \operatorname{Trp} B$ communication and cooperativity, the situation observed in $S 2$ species (T. acidophilum and T. volcanium) is probably the least complex one. Similarly archaic are the non operon-based $\operatorname{trpB2}$ genes of Sulfolobaceae, whereas the operon-based $\operatorname{tr} p B$ genes are more evolved. $s 1$ and $i 1 \_o 2$ species possess highly cooperative synthases. Thus, the archaeal tryptophan synthase (especially $\operatorname{trp} B$ variants) constitutes a model system for the study of protein complex formation. Due to different environmental conditions, several stages of cooperativity have been conserved, which allow to characterise the progress of $\operatorname{trp} A-\operatorname{trp} B$ coevolution based on gene expression and on functional cooperativity.

\section{Materials \\ Genomes and protein sequences}

Genomic content was determined by analysing version 6.2 of the STRING database [30].

All protein sequences were downloaded via the "Genome Project" database of the NCBI [55], which allows to access completely sequenced genomes. Respective COG tables were consulted to determine the COG group of genes [29] and to download sequences. Genes originating from the following completely sequenced genomes were analysed 
(abbreviations used for Figures and accession numbers of genomes in brackets):

\section{Crenarchaeota}

Aeropyrum pernix K1 (Aperni, NC_00854), Pyrobaculum aerophilum str. IM2 (Paerop, NC_003364), Sulfolobus acidocaldarius DSM 639 (Sacido, NC_007181), Sulfolobus solfataricus P2 (Ssolfa, NC_002754), Sulfolobus tokodaii str. 7 (Stokod, NC_003106).

\section{Euryarchaeota}

Archaeoglobus fulgidus DSM 4304 (Afulgi, NC_000917), Haloarcula marismortui ATCC 43049 (Hmaris, NC_006396), Halobacterium sp. NRC-1 (Halob, NC_002607), Methanocaldococcus jannaschii DSM 2661 (Mjanna, NC_000909), Methanococcoides burtonii DSM 6242 (Mburto, NC_007955), Methanococcus maripaludis S2 (Mmarip, NC_005791), Methanopyrus kandleri AV19 (Mkandl, NC_003551), Methanosarcina acetivorans C2A (Maceti, NC_003552), Methanosarcina barkeri str. Fusaro (Mbarke, NC_007355), Methanosarcina mazei Go1 (Mmazei, NC_003901), Methanosphera stadtmanae DSM 3091 (Mstadt, NC_007681), Methanospirillum hungatei JF1 (Mhunga, NC_007796) Methanothermobacter thermautotrophicus str. Delta H. (Mtherm, NC_000916), Natronomonas pharaonis DSM 2160 (Nphara, NC_007426), Picrophilus torridus DSM9790 (Ptorri, NC_005877), Pyrococcus abyssi GE5 (Pabyss, NC_000868), Pyrococcus furiosus DSM 3638 (Pfurio, NC_003413), Pyrococcus horikoshii OT3 (Phorik, NC_000961), Thermococcus kodakaraensis KOD1 (Tkodak, NC_006624), Thermoplasma acidophilum DSM1728 (Tacido, NC_002578), Thermoplasma volcanium GSS1 (Tvolca, NC_002689).

\section{Bacteria}

Escherichia coli K-12 (Ecoli, NC_000913), Geobacter metallireducens GS-15 (Gmetal, NC_007517), Geobacter sulfurreducens PCA (Gsulfu, NC_002939), Thermotoga maritima (Tmarit, NC_00853).

\section{Methods}

\section{Generating multiple sequence alignments}

For the generation of multiple sequence alignments (MSAs) the program M-Coffee [32] was used. It combines the output of nine individual MSA methods for the generation of a "meta"-MSA. M-Coffee has been shown to outperform all individual methods of MSA generation [32].

\section{Annotating multiple sequence alignments}

For each position in a MSA, residue conservation, secondary structure, the location of the interface area, active sites and residues, which are characteristic for sequence types, were determined and plotted. 3D-data were deduced from the PDB-file 1WDW, describing the TrpA/TrpB complex of P. furiosus [18]. For 2D-structure prediction, Jpred [37] was used. SDPpred [38] was utilised to identify those residues, which distinguished sequence groups due to their skewed or bimodal distribution. Annotations referring active site residues were deduced from the PDBsum page $[56,57]$, interface residues were annotated according to the Protein interfaces, surfaces and assemblies service PISA $[58,59]$. Both services were located at the webserver of the European Bioinformatics Institute (EMBL-EBI).

\section{Creating and evaluating phylogenetic trees}

SplitsTrees4 [33], a frame-work for phylogenetic analyses, was used to generate and analyse phylogenetic trees. MSAs originating from M-Coffee were utilised to calculate maximum likelihood protein distance estimates based on a JTT [60] model. The bio-neighbour joining approach [61] was used to generate trees. Resulting trees were analysed by bootstrapping (1000 replications each).

\section{Acknowledgements}

I want to thank Reinhard Sterner and Rüdiger Schmitt for stimulating discussions and their help in preparing this manuscript.

\section{References}

I. Yanofsky C: Using studies on tryptophan metabolism to answer basic biological questions. I Biol Chem 2003, 278(13): 10859-10878.

2. Yanofsky C: Advancing our knowledge in biochemistry, genetics, and microbiology through studies on tryptophan metabolism. Annu Rev Biochem 200I, 70:I-37.

3. Yanofsky C: Attenuation in the control of expression of bacterial operons. Nature 198I, 289(5800):75I-758.

4. Yanofsky C: The different roles of tryptophan transfer RNA in regulating trp operon expression in E. coli versus $B$. subtilis. Trends Genet 2004, 20(8):367-374.

5. Gutierrez-Preciado A, Jensen RA, Yanofsky C, Merino E: New insights into regulation of the tryptophan biosynthetic operon in Gram-positive bacteria. Trends Genet 2005, 2I(8):432-436.

6. Gast DA, Jenal U, Wasserfallen A, Leisinger T: Regulation of tryptophan biosynthesis in Methanobacterium thermoautotrophicum Marburg. J Bacteriol 1994, 176(15):4590-4596.

7. Xie Y, Reeve JN: Regulation of tryptophan operon expression in the archaeon Methanothermobacter thermautotrophicus. J Bacteriol 2005, I 87( ( 8):6419-6429.

8. Tang X, Ezaki S, Fujiwara S, Takagi M, Atomi H, Imanaka T: The tryptophan biosynthesis gene cluster trpCDEGFBA from Pyrococcus kodakaraensis KODI is regulated at the transcriptional level and expressed as a single mRNA. Mol Gen Genet 1999, 262(4-5):815-82I.

9. Bentley R: The shikimate pathway--a metabolic tree with many branches. Crit Rev Biochem Mol Biol 1990, 25(5):307-384.

10. Xie G, Keyhani NO, Bonner CA, Jensen RA: Ancient origin of the tryptophan operon and the dynamics of evolutionary change. Microbiol Mol Biol Rev 2003, 67(3):303-342.

II. Dunn MF, Aguilar V, Brzovic P, Drewe WF Jr., Houben KF, Leja CA, Roy $M$ : The tryptophan synthase bienzyme complex transfers indole between the a- and b-sites via a 25-30 A long tunnel. Biochemistry 1990, 29(37):8598-8607.

12. Weber-Ban E, Hur O, Bagwell C, Banik U, Yang LH, Miles EW, Dunn MF: Investigation of allosteric linkages in the regulation of tryptophan synthase: the roles of salt bridges and monovalent cations probed by site-directed mutation, optical spectroscopy, and kinetics. Biochemistry 200 I, 40(12):3497-35II.

13. Zalkin H, Smith JL: Enzymes utilizing glutamine as an amide donor. Adv Enzymol Relat Areas Mol Biol I998, 72:87-I44.

14. Wilmanns M, Hyde CC, Davies DR, Kirschner K, Jansonius JN: Structural conservation in parallel b/a-barrel enzymes that 
catalyze three sequential reactions in the pathway of tryptophan biosynthesis. Biochemistry 1991, 30(38):9161-9169.

15. Sterner R, Höcker B: Catalytic versatility, stability, and evolution of the (ba)8-barrel enzyme fold. Chem Rev 2005, I 05(I I):4038-4055

16. Brown JR, Doolittle WF: Archaea and the prokaryote-toeukaryote transition. Microbiol Mol Biol Rev 1997, 6 I (4):456-502.

17. Miles EW: Tryptophan synthase: a multienzyme complex with an intramolecular tunnel. Chem $\operatorname{Rec} 200 I$, I(2): I40-I5I.

18. Lee SJ, Ogasahara K, Ma J, Nishio K, Ishida M, Yamagata Y, Tsukihara $T$, Yutani K: Conformational changes in the tryptophan synthase from a hyperthermophile upon a2b2 complex formation: crystal structure of the complex. Biochemistry 2005 , 44(34): I |4|7-| | 427

19. Hioki Y, Ogasahara K, Lee S], Ma J, Ishida M, Yamagata Y, Matsuura Y, Ota M, Ikeguchi M, Kuramitsu S, Yutani K: The crystal structure of the tryptophan synthase b2 subunit from the hyperthermophile Pyrococcus furiosus. Investigation of stabilization factors. Eur J Biochem 2004, 27 I (13):2624-2635.

20. Kirschner K, Lane AN, Strasser AW: Reciprocal communication between the lyase and synthase active sites of the tryptophan synthase bienzyme complex. Biochemistry 1991, 30(2):472-478.

21. Miles EW, Rhee S, Davies DR: The molecular basis of substrate channeling. J Biol Chem 1999, 274(18): 12193-12196.

22. Schneider TR, Gerhardt E, Lee M, Liang PH, Anderson KS, Schlichting $\mathrm{I}$ : Loop closure and intersubunit communication in tryptophan synthase. Biochemistry 1998, 37(16):5394-5406.

23. Weyand $M$, Schlichting I: Crystal structure of wild-type tryptophan synthase complexed with the natural substrate indole-3-glycerol phosphate. Biochemistry 1999 38(50):16469-16480.

24. Osborne A, Teng Q, Miles EW, Phillips RS: Detection of open and closed conformations of tryptophan synthase by I5N-heteronuclear single-quantum coherence nuclear magnetic resonance of bound I-I5N-L-tryptophan. J Biol Chem 2003, 278(45):44083-44090.

25. Xie G, Forst C, Bonner C, Jensen RA: Significance of two distinct types of tryptophan synthase beta chain in bacteria, archaea and higher plants. Genome Biol 2002, 3(I):RESEARCH0004.

26. Leopoldseder S, Hettwer S, Sterner R: Evolution of multi-enzyme complexes: the case of tryptophan synthase. Biochemistry 2006, 45(47): $|4|||-|4| \mid 9$.

27. Merkl R: AMIGOS: a method for the inspection of genomic organisation or structure and its application to characterise and dissect conserved gene arrangements. In Silico Biol 2006, 6:28I-306.

28. Overbeek R, Fonstein M, D'Souza M, Pusch GD, Maltsev N: The use of gene clusters to infer functional coupling. Proc Natl Acad Sci U S A 1999, 96(6):2896-290I.

29. Tatusov RL, Fedorova ND, Jackson JD, Jacobs AR, Kiryutin B, Koonin EV, Krylov DM, Mazumder R, Mekhedov SL, Nikolskaya AN, Rao BS, Smirnov S, Sverdlov AV, Vasudevan S, Wolf YI, Yin J], Natale DA: The COG database: an updated version includes Eukaryotes. BMC Bioinformatics 2003, 4(I):4I.

30. von Mering C, Jensen LJ, Snel B, Hooper SD, Krupp M, Foglierini M Jouffre N, Huynen MA, Bork P: STRING: known and predicted protein-protein associations, integrated and transferred across organisms. Nucleic Acids Res 2005, 33(Database issue):D433-7.

31. Methe BA, Nelson KE, Eisen JA, Paulsen IT, Nelson W, Heidelberg JF, Wu D, Wu M, Ward N, Beanan MJ, Dodson RJ, Madupu R, Brinkac LM, Daugherty SC, DeBoy RT, Durkin AS, Gwinn M, Kolonay JF, Sullivan SA, Haft DH, Selengut J, Davidsen TM, Zafar N, White O, Tran B, Romero C, Forberger HA, Weidman J, Khouri H, Feldblyum TV, Utterback TR, Van Aken SE, Lovley DR, Fraser CM: Genome of Geobacter sulfurreducens: metal reduction in subsurface environments. Science 2003, 302(5652): 1967-1969.

32. Wallace IM, O'Sullivan O, Higgins DG, Notredame C: M-Coffee: combining multiple sequence alignment methods with $\mathrm{T}$ Coffee. Nucleic Acids Res 2006, 34(6): 1692-1699.

33. Huson DH, Bryant $\mathrm{D}$ : Application of phylogenetic networks in evolutionary studies. Mol Biol Evol 2006, 23(2):254-267.

34. Ciccarelli FD, Doerks T, von Mering C, Creevey CJ, Snel B, Bork P: Toward automatic reconstruction of a highly resolved tree of life. Science 2006, 3 I I (5765): | 283- I 287.
35. Altschul SF, Madden TL, Schaffer AA, Zhang J, Zhang Z, Miller W, Lipman DJ: Gapped BLAST and PSI-BLAST: a new generation of protein database search programs. Nucleic Acids Res 1997, 25(I 7):3389-3402.

36. Sander C, Schneider R: Database of homology-derived protein structures and the structural meaning of sequence alignment. Proteins |99I, 9(I):56-68.

37. Cuff JA, Clamp ME, Siddiqui AS, Finlay M, Barton GJ: JPred: a consensus secondary structure prediction server. Bioinformatics 1998, I 4( I 0):892-893.

38. Kalinina OV, Novichkov PS, Mironov AA, Gelfand MS, Rakhmaninova $A B$ : SDPpred: a tool for prediction of amino acid residues that determine differences in functional specificity of homologous proteins. Nucleic Acids Res 2004, 32(Web Server issue):W424-8.

39. Hettwer S, Sterner R: A novel tryptophan synthase b-subunit from the hyperthermophile Thermotoga maritima. Quaternary structure, steady-state kinetics, and putative physiological role. J Biol Chem 2002, 277(10):8194-820I.

40. Alves R, Savageau MA: Evidence of selection for low cognate amino acid bias in amino acid biosynthetic enzymes. Mol Microbiol 2005, 56(4): 1017-1034

4I. Ohno S: Evolution by gene duplication. Heidelberg, Springer; 1970.

42. Kondrashov FA: In search of the limits of evolution. Nat Genet 2005, 37(I):9-10.

43. Jensen RA: Enzyme recruitment in evolution of new function. Annu Rev Microbiol 1976, 30:409-425.

44. Xie G, Bonner CA, Song J, Keyhani NO, Jensen RA: Inter-genomic displacement via lateral gene transfer of bacterial trp operons in an overall context of vertical genealogy. BMC Biol 2004, 2:15.

45. Gupta RS: Protein phylogenies and signature sequences: A reappraisal of evolutionary relationships among archaebacteria, eubacteria, and eukaryotes. Microbiol Mol Biol Rev 1998, 62(4): | $435-149 \mid$

46. Snel B, Bork P, Huynen MA: Genomes in flux: The evolution of archaeal and proteobacterial gene content. Genome Res 2002, I 2(I): 17-25.

47. Price MN, Arkin AP, Alm EJ: The life-cycle of operons. PLOS Genetics 2006, 2(6):e96.

48. MerkI R: SIGI: score-based identification of genomic islands. BMC Bioinformatics 2004, 5:22.

49. Huber H, Hohn MJ, Stetter KO, Rachel R: The phylum Nanoarchaeota: present knowledge and future perspectives of a unique form of life. Res Microbiol 2003, I54(3):|65-I7|.

50. Ruepp A, Graml W, Santos-Martinez ML, Koretke KK, Volker C, Mewes HW, Frishman D, Stocker S, Lupas AN, Baumeister W: The genome sequence of the thermoacidophilic scavenger Thermoplasma acidophilum. Nature 2000, 407(6803):508-5।3.

5I. Omelchenko MV, Makarova KS, Wolf YI, Rogozin IB, Koonin EV: Evolution of mosaic operons by horizontal gene transfer and gene displacement in situ. Genome Biol 2003, 4(9):R55.

52. Makarova KS, Ponomarev VA, Koonin EV: Two C or not two C: recurrent disruption of Zn-ribbons, gene duplication, lineage-specific gene loss, and horizontal gene transfer in evolution of bacterial ribosomal proteins. Genome Biol 200I, 2(9):RESEARCH 0033.

53. Di Giulio M: The universal ancestor and the ancestor of bacteria were hyperthermophiles. J Mol Evol 2003, 57(6):72I-730.

54. Gribaldo $S$, Brochier-Armanet $C$ : The origin and evolution of Archaea: a state of the art. Philos Trans R Soc Lond B Biol Sci 2006, 36I(1470): 1007-1022.

55. NCBI_Genomes: NCBI complete microbial genomes. [http:// www.ncbi.nlm.nih.gov/genomes/lproks.cgi]

56. Laskowski RA, Chistyakov VV, Thornton JM: PDBsum more: new summaries and analyses of the known 3D structures of proteins and nucleic acids. Nucleic Acids Res 2005, 33(Database issue): D266-8.

57. PDBsum: PDBsum home page. [http://www.ebi.ac.uk/thorntonsrv/databases/pdbsum/]

58. Krissinel E, Henrick K: Detection of protein assemblies in crystals. Edited by: Berthold MR. Springer, Heidelberg; 2005: 163-174.

59. EBI_PISA: EBI PISA home page. [http://www.ebi.ac.uk/msd-srv/ prot int/pistart.html]. 
60. Jones DT, Taylor WR, Thornton JM: The rapid generation of mutation data matrices from protein sequences. Comput Appl Biosci 1992, 8(3):275-282.

61. Gascuel O: BIONJ: an improved version of the NJ algorithm based on a simple model of sequence data. Mol Biol Evol 1997, 14(7):685-695.

Publish with Bio Med Central and every scientist can read your work free of charge

"BioMed Central will be the most significant development for disseminating the results of biomedical research in our lifetime. " Sir Paul Nurse, Cancer Research UK

Your research papers will be:

- available free of charge to the entire biomedical community

- peer reviewed and published immediately upon acceptance

- cited in PubMed and archived on PubMed Central

- yours - you keep the copyright

Submit your manuscript here:

http://www.biomedcentral.com/info/publishing_adv.asp
BioMedcentral 